\title{
Review Article \\ Environmental Impact on DNA Methylation in the Germline: State of the Art and Gaps of Knowledge
}

\author{
Francesca Pacchierotti and Marcello Spanò \\ Laboratory of Toxicology, Technical Unit of Radiation Biology and Human Health, CR Casaccia, ENEA, \\ Via Anguillarese 301, 00123 Rome, Italy
}

Correspondence should be addressed to Francesca Pacchierotti; francesca.pacchierotti@enea.it

Received 14 January 2015; Accepted 3 May 2015

Academic Editor: Heide Schatten

Copyright (C) 2015 F. Pacchierotti and M. Spanò. This is an open access article distributed under the Creative Commons Attribution License, which permits unrestricted use, distribution, and reproduction in any medium, provided the original work is properly cited.

The epigenome consists of chemical changes in DNA and chromatin that without modifying the DNA sequence modulate gene expression and cellular phenotype. The epigenome is highly plastic and reacts to changing external conditions with modifications that can be inherited to daughter cells and across generations. Whereas this innate plasticity allows for adaptation to a changing environment, it also implies the potential of epigenetic derailment leading to so-called epimutations. DNA methylation is the most studied epigenetic mark. DNA methylation changes have been associated with cancer, infertility, cardiovascular, respiratory, metabolic, immunologic, and neurodegenerative pathologies. Experiments in rodents demonstrate that exposure to a variety of chemical stressors, occurring during the prenatal or the adult life, may induce DNA methylation changes in germ cells, which may be transmitted across generations with phenotypic consequences. An increasing number of human biomonitoring studies show environmentally related DNA methylation changes mainly in blood leukocytes, whereas very few data have been so far collected on possible epigenetic changes induced in the germline, even by the analysis of easily accessible sperm. In this paper, we review the state of the art on factors impinging on DNA methylation in the germline, highlight gaps of knowledge, and propose priorities for future studies.

\section{Introduction}

Epigenetics formally refers to heritable changes in gene expression and in phenotype occurring without changes in the underlying DNA sequence. Alterations in epigenetic marks have been involved in the etiology of complex syndromes and diseases, including cancer, infertility, cardiovascular, respiratory, metabolic, immunologic, and neurodegenerative pathologies [1-3]. The main epigenetic mechanisms responsible for these alterations are represented by DNA methylation, posttranslational histone modifications, and regulation by noncoding microRNAs [4]. In particular, DNA methylation, the most studied epigenetic mark so far, involves the enzymatically mediated covalent addition of a methyl group to the C5 position of cytosine, forming 5-methyl cytosine $(5-\mathrm{mC})$. Cytosine methylation primarily happens in $\mathrm{CpG}$ dinucleotides in $\mathrm{CpG}$-rich sequences, dubbed as CpG islands, often occurring near or in the gene promoter regions. DNA methylation, operated by a family of DNA methyltransferases [5], is implicated in many life-essential cellular and developmental processes, such as embryonic reprogramming, cellular differentiation, silencing of genes and transposons, parental imprinting, $\mathrm{X}$ chromosome inactivation, and genomic stability [6-8].

It is largely accepted that exposure to a variety of environmental toxicants has a negative impact on human health and contributes to the development of a large array of diseases. The epigenome is more plastic and flexible than the genome. Changes of epigenetic marks, such as DNA methylation, can affect the chromatin structure and modify binding of transcription factors and gene expression. The theoretical framework of a changing environment and a modifiable epigenome might offer unexplored and unsuspected ways to understand gene-environment interactions and potentially mitigate the impact of environmental toxicants on human health $[9,10]$. 
A rapidly growing number of epidemiological studies have been carried out throughout the world, in which environmental exposure and lifestyle (an umbrella term including diet, behavior, stress, physical activity, working habits, voluntary alcohol and tobacco consumption, etc.), meshed with the genetic background, have been associated with epigenetic changes, mostly DNA methylation (reviewed in [11-18]). The trend in the field appears to shift from the introduction of a novel "proof-of-principle" approach in toxicology to a more systematic scientific specialty $[19,20]$.

Environmental epidemiology research is addressing epigenetic mechanisms as mediators of environmental exposure on disease risk or just as biosensors of exposure even if not mechanistically relevant. Because stable methylation marks at differentially methylated regions (DMRs) regulating imprinted genes are acquired before gastrulation, they may serve as archives of early exposure with the potential to improve our understanding of developmental origin of adult diseases.

DNA methylation has been by far the most extensively measured epigenetic mark because of its obviously fundamental biological interest, its mitotic stability, the availability of methods for its quantification, globally or in targeted regions, its stability during the DNA extraction and purification procedures, and its durability in archival biological materials. By and large, the strategy consists of comparatively assessing the methylation differences at $\mathrm{CpG}$ islands in gene promoters or DMRs, between control and exposed groups.

The information on DNA methylation status and changes in association with environmental exposure and lifestyle has been mostly collected from peripheral blood leukocytes (PBL), which can be sampled by a minimally invasive approach. However, tissue specificity, together with purity of cells for DNA methylation determination, represents a relevant issue in epigenetic studies as each tissue and, within a tissue, probably each cell type have its own epigenetic profile.

During our lifetime, the genome undergoes two main epigenomic reprogramming periods, each of which involves waves of DNA demethylation and de novo methylation. These precise and coordinated genome-wide reprogramming steps are associated with pivotal developmental stages like the establishment of cell totipotency and the differentiation of the germ cell lineages $[21,22]$. The first wave occurs, with notable differences between sexes, in all cells of the preimplantation embryo. The second wave occurs in primordial germ cells (PGCs) only; this time the demethylation events are more radical and involve imprinted genes whose allelic-specific methylation is first erased and then reset according to the sex of the germline [23]. Conceivably, these phases of mammalian development are especially sensitive to environmental stressors, which can impact epigenetic plasticity with potential enduring effects on metabolic pathways and disease susceptibility. Indeed, such scenario would be in agreement with the theory of the fetal basis of adult onset disease [24-26].

The early fetal period of life is particularly critical for gonadal development, and many common reproductive disorders of the adult male, such as infertility and testis cancer, have been proposed to have a fetal origin [27]. In addition, prenatal exposure to environmental contaminants, especially those belonging to the variegated and heterogeneous class of compounds collectively defined as endocrine disruptors (EDs), has been linked to the increased incidence of male reproductive pathologies [28-32]. The interference with developmental epigenetic processes has been evoked as one of the potential mechanisms of EDs action affecting the integrity of the male reproductive system [33]. Recent evidence that unbalanced one carbon metabolism may impact male reproductive health [34] and that a variety of epigenetic markers, including global or gene-specific DNA methylation, can be altered in infertility patients $[35,36]$ is in agreement with this hypothesis.

In spite of the extensive DNA demethylation occurring in preimplantation embryonic cells, there are sequences, corresponding primarily, but not exclusively, to parentally imprinted genes that escape global demethylation [37, 38]. This means that changes of DNA methylation induced by environmental stressors in germ cells could not only have consequences for the reproductive health of the exposed individual but also might be potentially heritable from one generation to another and might cause transgenerational adverse effects by a nongenetic mechanism of inheritance.

Notwithstanding the knowledge about epigenetic regulation of gonadal development and the evidence about epigenetic changes induced in rodent germline by several chemicals or dietary conditions, the number of studies aimed at testing possible effects of lifestyle or chemical exposure on human sperm DNA methylation is extremely limited in comparison to the number of studies carried out on blood cells. Sperm can be obtained by a similarly noninvasive procedure; they represent the target cell for male reproductive effects and not merely a surrogate of it; their ultimate DNA methylation pattern is acquired by a multistep process started in PGCs and completed during the spermatogonia and spermatocyte differentiation phases $[39,40]$, which might therefore be repeatedly exposed to environmental insults. For all these reasons it would be very valuable to extend the analysis of sperm epigenetics beyond infertility clinical investigation to environmental biomonitoring studies.

Focus of this literature review will be on data linking various exogenous factors, from specific chemical exposure to psychological stress, to DNA methylation changes in the germline and their consequences in the offspring. We have taken into consideration both experimental rodent and human studies. In addition, due to the very limited amount of data from human biomonitoring investigations, we have decided to include a survey of papers reporting human population studies which have shown an environmental impact on DNA methylation of somatic cells, to highlight those sources of exposure that would be worth further germline-oriented investigations, and the present gaps of knowledge.

\section{Human Studies on Environmentally Linked DNA Methylation Changes in Somatic and Germ Cells}

Several recent and excellent reviews $[12,13,15,17,41,42]$ have been published on this subject. Here, we try to offer an 
original aggregation pattern of the data, which are mostly very recent but often incomplete and methodologically heterogeneous, to highlight research trends and gaps of knowledge, also in relation to experimental rodent studies. The epidemiological studies specifically reporting the effects of environmental chemicals on DNA methylation are summarized in Table 1.

\subsection{Metals: Arsenic, Chromium, Cadmium, Lead, Mercury,} and Selenium. Environmental toxic metals have been associated with important human pathologies like cancer, cardiovascular and autoimmune diseases, and neurological disorders and, recently, their impact on the epigenome has started to be explored [43].

Inorganic arsenic is a carcinogenic metal. Several millions of people around the world are exposed to arsenic concentrations in their drinking water that exceed the World Health Organization's recommended limit of $10 \mathrm{ppb}$. The mechanism(s) of arsenic toxicity and carcinogenicity are not fully clarified; recently, epigenetic alterations have been proposed to play a role and have been explored in cohort and case-control studies, especially in Asian populations living in highly contaminated areas (reviewed in [44]). Exposure, generally assessed by the metal concentration in drinking water and/or in biological fluids or tissues, has been associated with dose-dependent global DNA hypermethylation [45-47] and with hypermethylation of specific oncosuppressor genes [48-52]. Genome-wide comparisons of DNA methylation patterns from people who developed skin lesion and a control group in Bangladesh have evidenced $6 \mathrm{CpG}$ sites with greatest changes of DNA methylation among cases, one of which belongs to the RHBDF1 gene, previously reported to be hypermethylated in arsenic-exposed cases [53]. Similarly, by using high throughput approaches, specific DNA methylation changes in particular genes were detected between arsenicinduced and non-arsenic-induced urothelial carcinomas in Taiwan [54].

The epigenetic effects of in utero arsenic exposure were investigated in umbilical cord blood to find out a mechanistic basis for possible arsenic-induced alterations of fetal developmental programming. Hypermethylation of the transposonic repeat LINE-1, p16 promoter, and other specific sequences was associated with arsenic concentration in maternal drinking water $[55,56]$. Other studies also showed some effects of arsenic maternal exposure on cord blood DNA methylation $[57,58]$, although the involved sequences were not always consistent.

The newborn blood DNA methylation pattern seems to be affected also by in utero exposure to low concentrations, as shown by the results of a prospective American birth cohort study using high throughput arrays [59]. In another large Mexican cohort, a total of 2,705 genes in cord blood leukocytes showed differences in DNA methylation that were associated with maternal exposure to arsenic in drinking water. The gene set was highly enriched in binding sites of the early growth response and CTCF transcription factors. Furthermore, DNA methylation levels of seven of these genes were associated with differences in birth outcomes including gestational age, placental weight, and head circumference
[60]. These results strongly point to the need for long-term follow-ups to determine whether the observed DNA methylation changes may be associated with specific health outcomes.

Chromium VI [61], mercury [62, 63], lead [64, 65], cadmium [62,66], and selenium [67] are other metals for which association studies between human exposure and DNA methylation changes, mainly in peripheral blood cells, have been conducted. Cadmium can cross the placental barrier and its potential as a developmental toxicant has been studied in an American survey by comparing maternal blood cadmium levels during pregnancy and genome-wide DNA methylation in leukocyte DNA collected from cord blood cells [68]. A variety of genes showed methylation changes associated with maternal cadmium concentrations. The set was enriched in genes involved in transcriptional regulation control and apoptosis. Conserved DNA motifs with sequence similarity to specific transcription factor binding sites were identified within the CpG islands of the gene set. Altogether the results pointed to a possible functional impact of cadmium on fetal DNA methylation.

Overall, the number of studies on the epigenetic impact of environmental metal exposure is limited. The study designs, the number of people enrolled, the genomic sequences investigated, and the methods used to assess methylation changes (locus-specific, global locus-independent, epigenome-wide) are quite heterogeneous. Widely different exposure levels have been evaluated in occupational studies and in studies on the general population. Therefore, any attempt to draw general conclusions is still premature. However, the expected decrease of costs of epigenome-wide analytical methods will likely allow acquiring a wealth of data in the near future. In addition to such unsupervised studies, more focused investigations on global hypomethylation and downregulation of the methylation machinery, hypomethylation in regions controlling transposons or oncogene expression, or hypermethylation at oncosuppressor genes could offer the best contribution to unravel epigenetic mechanisms underlying environmental cancer and to develop novel predictive biomarkers.

\subsection{Air Pollution (Particulate Matter, Polycyclic Aromatic} Hydrocarbons, Benzene, and Volatile Organic Compounds). Exposure to air pollution is a side-product of urbanization and industrialization representing a dramatic health problem, associated with childhood asthma, wheeze, and increased cardiovascular morbidity and mortality. It is generally assessed by measuring the levels of particulate matter with aerodynamic diameter $\leq 2.5$ (PM2.5) or $\leq 10 \mu \mathrm{m}$ (PM10) together with the levels of other air pollutants like black carbon, ozone, polycyclic aromatic hydrocarbons (PAHs), sulfur, and nitrogen dioxide. There have been several studies carried out across the globe, which have considered possible impacts of air pollution on DNA methylation with sometime contrasting results [69].

In a recent European study on a cohort of young nonsmoking subjects, the exposure to ambient concentrations of $\mathrm{NO}_{2}, \mathrm{PM} 10, \mathrm{PM} 2.5$, and $\mathrm{O}_{3}$ and traffic parameters were associated with a decreased global DNA methylation level in blood cells [70]. 


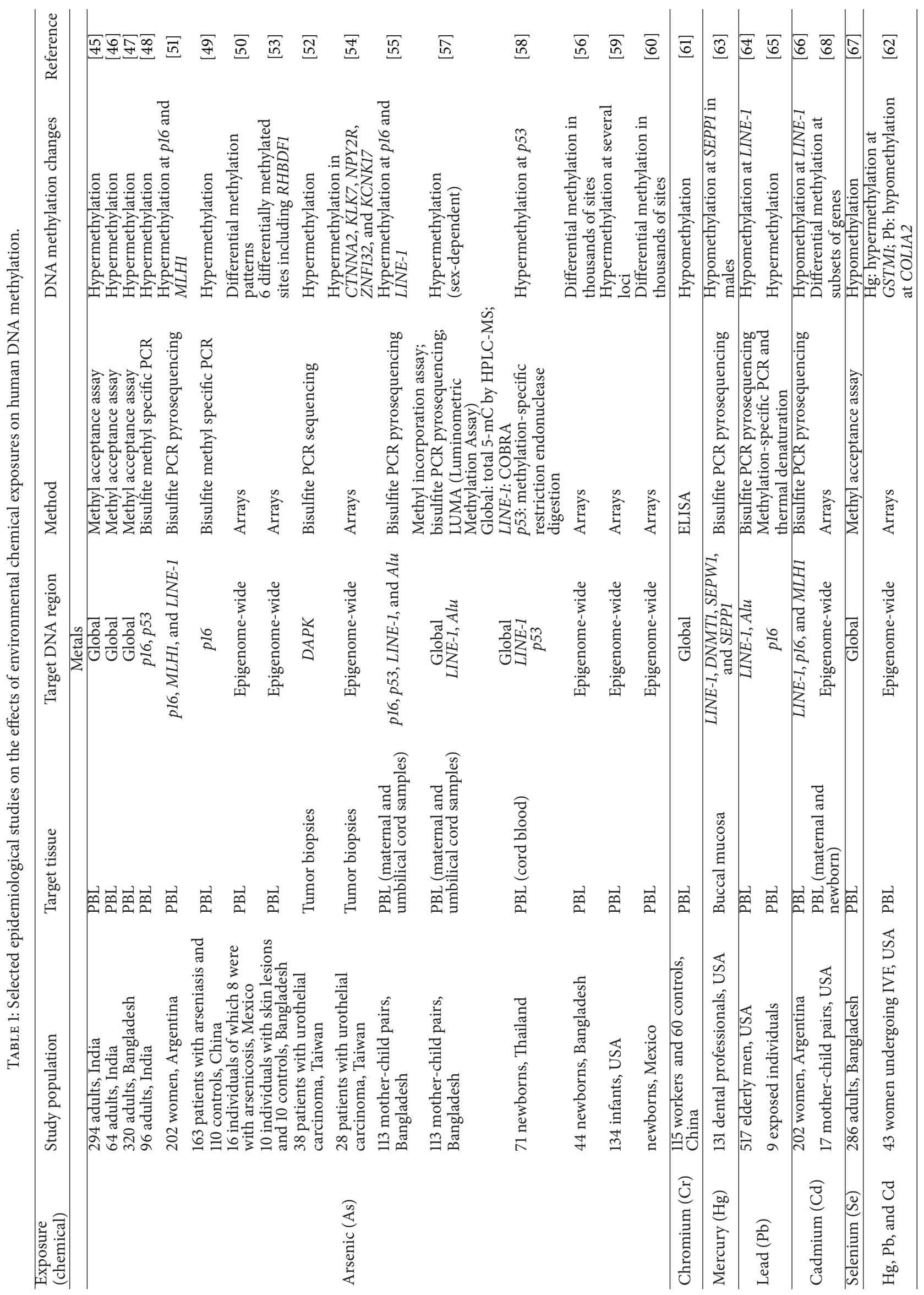




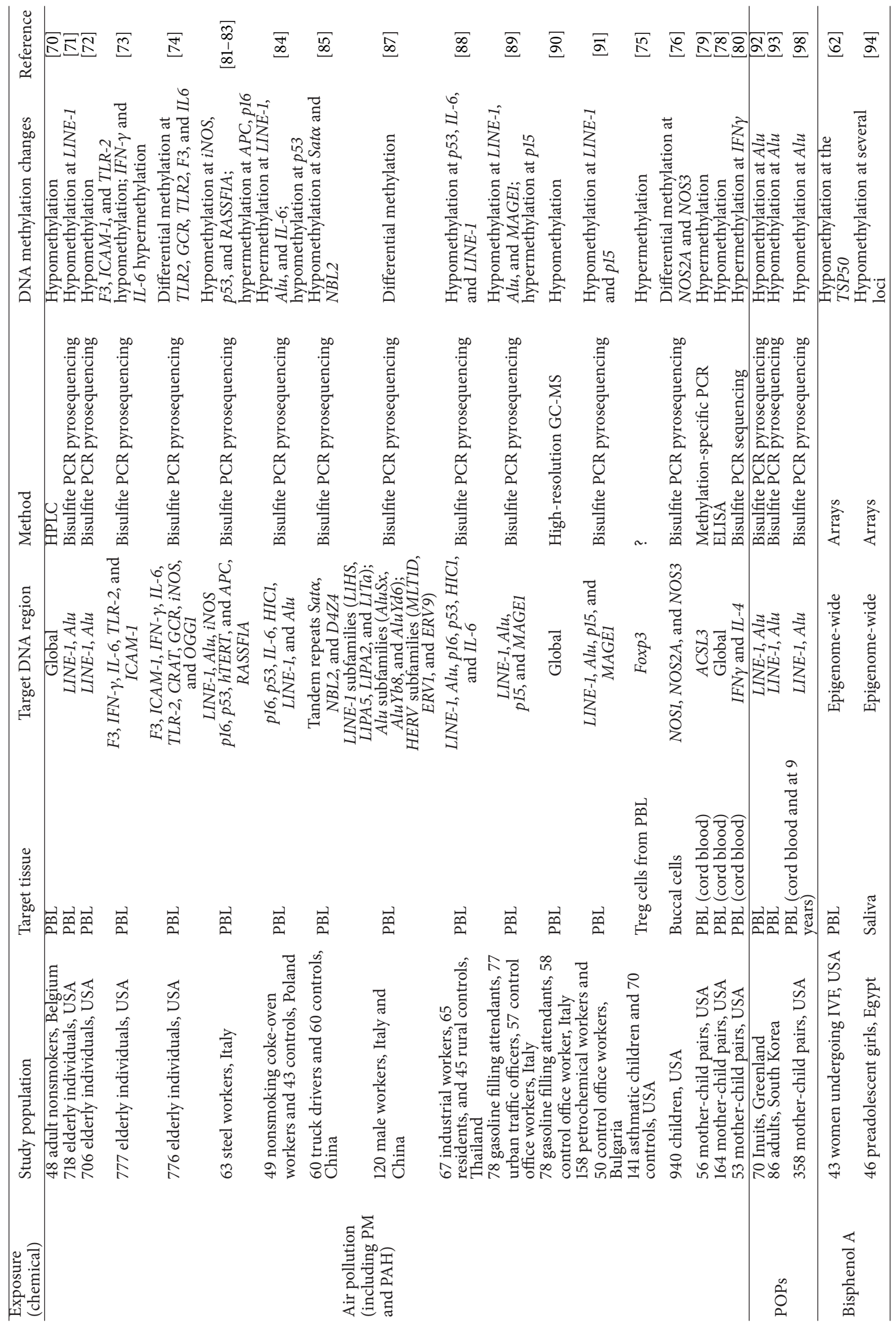




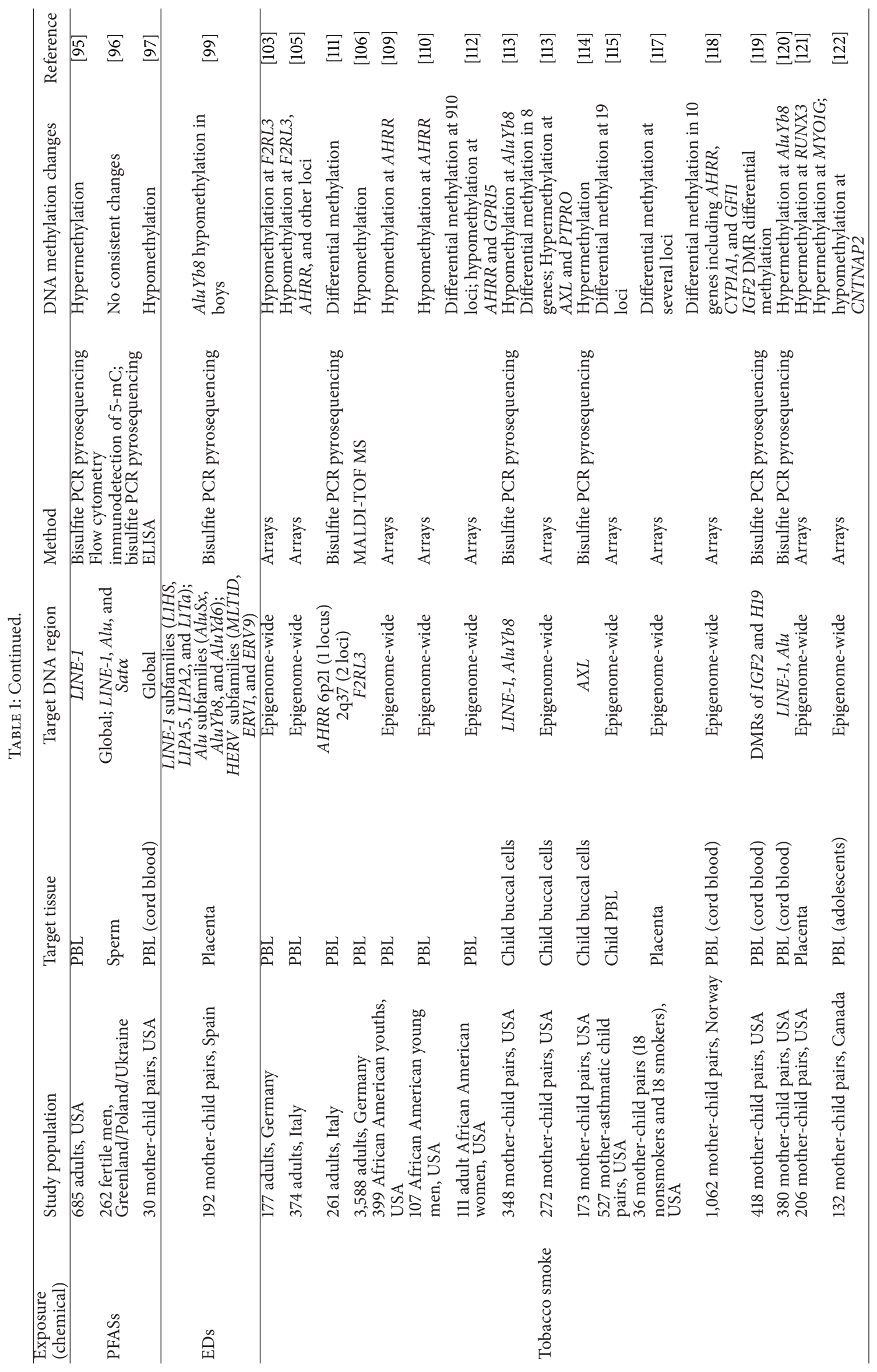


Numerous studies focused on the vulnerable subpopulation of elderly people [71-74]. Hypomethylation of repeated sequences ( $L I N E-1$ and, in some cases, also Alu) was reported to be associated with increased pollutant concentrations. In addition, methylation changes of specific genes involved in inflammatory and immune response pathways were observed, which were regarded as modifiers of the association between air pollutants and reduced lung function [74].

Other studies investigated effects of air pollution on DNA methylation in children, showing changes in genes involved in asthma morbidity [75] or nitric oxide metabolism in airways [76, 77].

Lower global DNA methylation [78] and hypermethylation of specific genes $[79,80]$ in umbilical cord white blood cells were shown to be associated with maternal exposure to airborne PAHs, pointing to a possible prenatal environmental epigenetic origin of childhood diseases.

Workers of different job sectors, exposed to particulate matter, PAHs, and benzene, have been also monitored for possible DNA methylation changes in peripheral blood cells [81-91]. In general, DNA repetitive elements, such as LINE1, Alu, and $H E R V$, have been analyzed, in addition to specific genes including $p 53, p 15, p 16, A P C, R A S S F 1 A, H I C 1$, $i N O S, h T E R T$, and $I L-6$. Each specific gene and subfamily of repetitive sequences seem to respond independently to the exposure and no set of sequences has yet emerged as an ideal reporting system of epigenetic effects. In addition, exposure conditions and methods of assessment were quite heterogeneous making any overall conclusion impossible. These studies support the notion that epigenetic biomonitoring is still a new area of environmental health studies that necessitates of international coordination, methodological harmonization, and mechanistically sound interpretation of results.

2.3. Persistent Organic Pollutants (POPs) and Endocrine Disruptors (EDs). This heterogeneous class of chemicals is strongly suspected to interfere with the human hormonal homeostasis and to hamper reproductive integrity, especially when exposure occurs during the pre- and perinatal life stages. In a cohort of Greenland Inuits, in DNA extracted from blood samples, Alu sequences showed significant hypomethylation as a function of increasing blood concentration of $\mathrm{p}, \mathrm{p}^{\prime}$-DDT [1,1,1-trichloro-2,2-bis(pchlorophenyl)ethane], its main metabolites $\mathrm{p}, \mathrm{p}^{\prime}-\mathrm{DDE}$ [1,1-dichloro-2,2-bis(p-chlorophenyl)ethylene], $\quad \beta$-HCH (hexachlorocyclohexane), oxy- and $\alpha$-chlordane, mirex, sum of PCBs (polychlorinated biphenyls), and sum of POPs; the methylation level of LINE-1 sequences showed a similar inverse trend with the exposure, albeit not statistically significant [92]. In agreement with these data, the blood concentrations of various organochlorine pesticides in a cohort of healthy Koreans were inversely associated with the methylation level of Alu but not of LINE-1 sequences [93].

Another widely debated chemical is the ubiquitous bisphenol A (BPA), a monomer used in epoxy resins and polycarbonate plastics. Exposure to BPA and possible methylation alterations were studied with genome-wide approaches. Significant hypomethylation of the TSP50 gene promoter in blood cells was associated with BPA exposure in a cohort of women undergoing in vitro fertilization (IVF) [62]. In a survey of prepubescent Egyptian girls [94] higher urinary BPA concentrations were associated with lower genomic methylation and, interestingly, many affected genes were among those whose expression changes had been previously associated with BPA exposure.

Another class of emerging POPs is represented by perfluoroalkyl substances (PFASs), which include a variety of compounds widely used in many industrial processes and products. Cross-sectional associations between serum PFASs and LINE-1 DNA methylation were evaluated in an American population highly exposed via contaminated drinking water [95]. A significant association was found for some but not all specific PFASs. To explore the possible effects on male reproduction, global methylation and LINE-1, Alu, and Sat $\alpha$ methylation levels were directly assessed in sperm DNA from fertile men from Greenland, Poland, and Ukraine characterized by a wide contrast to PFASs plasma levels. No strong consistent associations between PFASs exposure and any of the sperm methylation biomarkers could be detected [96].

Three studies explored the influence of maternal POPs serum concentrations on DNA methylation of umbilical cord blood cells. Global DNA hypomethylation appeared to be associated with the serum level of specific PFASs [97]. Interestingly, two studies examining the effects on various families of repeated DNA sequences [98, 99] showed that the association between serum xenoestrogen contamination and Alu hypomethylation in cord blood was influenced by the baby gender, in agreement with the hypothesis of a differential, gender-dependent, susceptibility to prenatal EDs exposure.

2.4. Antibiotics. Low birth weight (LBW) has been associated with common adult-onset chronic diseases. Its etiology is multifactorial and exposure to antibiotics has been reported to increase LBW risk. Among possible mechanisms underlying this association, epigenetic changes have been proposed.

In the US Newborn Epigenetics Study (NEST), the methylation status of the DMRs of a variety of growth regulatory imprinted genes (IGF2, H19, MEST, PEG3, PLAGL1, SGCE/PEG10, NNAT, and MEG3) was analyzed, in umbilical cord blood cells, in relation to the infant birth weight and maternal (self-reported) antibiotic use. Methylation at IGF2, H19, PLAGL1, MEG3, and PEG3 was associated with maternal antibiotic use, although only methylation at the PLAGL1 DMR was also associated with birth weight [100].

2.5. Tobacco Smoke. The potential epigenetic links between current and prenatal smoking and smoking-related diseases are extensively discussed in recent review papers [101, 102]. Smokers and nonsmokers have been compared by high throughput methods in several cohorts of adult and young people, with some consistent alterations detected involving DNA methylation differences at specific positions in the F2RL3 [103-107], in the AHRR [108-112], and in GPR15 genes [112], which emerged as strong candidates to predict smoking-related negative health outcomes. Epigenetic 
changes in the offspring of mothers smoking during pregnancy have been characterized by genome wide approaches, to contribute unraveling the mechanistic pathways of some, well-known, prenatal smoking-related adverse effects. Accumulating data indicate that prenatal exposure to tobacco smoke is associated with reproducible epigenetic changes at a global and gene-specific level that persist well in childhood and adolescence [97, 113-122]. Changes have been found, among others, in genes involved in transcription, in oxidative stress and detoxification pathways, and in repetitive elements, even though the biological significance of a variety of altered loci remains to be understood.

\subsection{Parental Influence}

2.6.1. Paternal Effects. In humans, there is sparse evidence linking lifestyle paternal factors with the offspring epigenome [123]. Paternal obesity has been associated with hypomethylation at the IGF2 [124] and MEST, PEG3 and NNAT [125] DMRs in the offspring cord blood cells, independently of maternal obesity and other potential confounders.

It is noteworthy that global sperm DNA methylation has been shown to increase, on average, by $1.76 \%$ per year [126], and an in-depth analysis of the methylome in two sperm samples collected 9-19 years apart from 17 fertile American men has shown several age-related changes [127]. One hundred and thirty-nine regions were significantly and consistently hypomethylated and 8 regions were significantly hypermethylated with age; 117 genes were associated with these regions of methylation alterations (promoter or gene body), with a portion of them surprisingly located at genes previously associated with schizophrenia and bipolar disorder. In the same samples, LINE-1 showed global hypermethylation with age, while another study, aimed at relating numerous variables with sperm DNA methylation [128], did not show age-dependent changes in LINE-1, Alu, and Sat $\alpha$ methylation level, probably because of the narrow age contrast of studied populations. In the latter study, personal characteristics and habits, body mass index (BMI), semen quality parameters, sperm chromatin integrity, biomarkers of accessory gland function, and the plasma concentration of reproductive hormones were related to sperm DNA methylation in a cohort of 224 men of proven fertility, living in three European regions, Greenland, Warsaw, and Kharkiv. The geographical location emerged as the main determinant of the methylation level in repetitive sequences and no other consistent associations between methylation markers and the assessed variables were identified across countries [128].

Until now, only three human biomonitoring studies addressed the impact of environmental factors on sperm DNA methylation. One is the already cited investigation on the possible effects of PFASs exposure on LINE-1, Alu, and Sat $\alpha$ methylation level [96], which did not show consistent PFASs-associated alterations. The other two studies focused on occupational radiation exposure and alcohol consumption. An increase of hypermethylated spermatozoa was shown in radiation-exposed workers [129]. Some years ago, alcohol had been shown to reduce the methyltransferase mRNA levels in sperm of chronically treated rats with potential consequences on paternal imprinting [130]. Notably, a trend of increased demethylation with alcohol consumption was shown, in sperm of male volunteers, at the $H 19$ and IG DMRs, with a significant difference observed at the $I G$-DMR between the nondrinkers and heavy alcohol consumers [131].

2.6.2. Maternal Effects. Newborn methylomes contain molecular memory of the individual in utero experience [132]. In the above chapters we have discussed various examples linking maternal environmental exposure to newborn DNA methylation, as assessed through cord blood cell analysis. However, the maternal impact appears to extend beyond that of specific chemical contaminants, as also metabolism, nutrition, and stress seem to influence the offspring methylome.

In an American black mother-child cohort study, genome-wide analysis of cord blood cells showed that about $20 \mathrm{CpG}$ sites in cancer and cardiovascular disease relevant genes were highly significantly associated with maternal BMI [133].

The epigenetic consequences of prenatal famine and caloric restriction have been evaluated in a cohort of people conceived in the winter 1944-45 during a severe famine at the end of World War II (Dutch Hunger Winter Families Study). These people appear to bear the consequences of prenatal stress later in life, including an adverse metabolic profile (suboptimal glucose handling, higher BMI, and elevated total and low-density lipoprotein cholesterol) and increased risk of schizophrenia. While the overall global methylation levels in their blood cells appear to be unaffected [134], significant DNA methylation changes have been shown, at several specific loci corresponding to imprinted genes or to genes implicated in growth and metabolic diseases, including IGF2, IL-10, LEP, ABCA1, GNASAS, and MEG3 [135-139]. A genome-scale analysis has demonstrated that differential DNA methylation preferentially occurs at regulatory regions and maps to genes enriched for differential expression during early development [140]. Changes have been also shown to depend on the sex of the exposed individual and the gestational timing of the exposure [137].

Folate plays an essential role in one-carbon metabolism involving remethylation of homocysteine to methionine, which is a precursor of $S$-adenosylmethionine, the primary methyl group donor for most biological methylations, including DNA methylation. A few pilot studies considered possible effects of maternal intake of methyl-donor compounds on their infant DNA methylation. Compared to infants born to women reporting no folic acid intake before or during pregnancy, methylation levels at the H19 DMR in umbilical cord blood leukocytes decreased with increasing folic acid intake, the decrease most pronounced in the male offspring [141]. In another study [142], increased methylation at the maternally IGF2 imprinted gene and decreased methylation at the maternally imprinted gene PEG3 and at the repetitive transposonic sequence $L I N E-1$ were associated with folic acid supplementation after the 12th week of gestation but not during the first trimester or before conception. Finally, a third study [143] did not detect any major association between intake of methyl donor nutrients (vitamin B12, betaine, 
choline, folate, $\mathrm{Cd}, \mathrm{Zn}$, and $\mathrm{Fe}$ ) during pregnancy and LINE-1 DNA methylation.

The results of a human epidemiological study, conducted in rural populations in Gambia experiencing pronounced seasonal fluctuations in nutritional status and diet, support a role for periconceptional maternal plasma concentration of key micronutrients involved in one-carbon metabolism on infant DNA methylation $[144,145]$. The study focused on the analysis of human candidate metastable epiallelic loci $[25,146]$. Metastable epialleles are genomic regions where epigenetic patterning occurs before gastrulation in a stochastic fashion leading to systematic interindividual variation within one species. Their existence is well documented in the mouse since the pioneering studies on the agouti viable yellow $\left(A^{v y}\right)$ locus, and, in this model, maternal diet has been shown to modulate the establishment of the epigenetic marks (reviewed in [38]). The human survey has shown that DNA methylation at metastable epialleles in lymphocytes and hair follicle cells of infants conceived during the rainy ("hungry") season is significantly different from that of infants conceived in the dry ("harvest") season, providing first evidences of a lasting and systemic effect of periconceptional environment on human epigenotype.

Maternal depression has been associated with a higher risk of LBW and hypermethylation at the MEG3 DMR of infants [147]. Furthermore, LBW infants had lower methylation at the IGF2 DMR, while high birth weight infants had higher methylation at the PLAGL1 DMR compared with normal birth weight infants. Thus, imprinted gene plasticity may play a role in the observed association between depressive mood in pregnancy and LBW.

Preliminary human studies are providing first evidence supporting the conclusion that traumatic experiences can result in lasting, broad, and functionally organized DNA methylation signature in several tissues in offspring. A Canadian study (Project Ice Storm) was set up some months after the 1998 Quebec ice storm by recruiting women who had been pregnant during the disaster, scoring their degrees of objective hardship and subjective distress. Thirteen years later, genome-wide DNA methylation profiling in T cells obtained from 36 of the children was assessed. Prenatal maternal objective hardship (but not maternal subjective distress) was correlated with DNA methylation levels in 1675 CpGs affiliated with 957 genes predominantly related to immune function [148].

\section{Rodent Experimental Studies on the Induction of Epigenetic Changes in the Germline}

In the last few years, experiments in rodents started to test the hypothesis that exogenous exposure to some measurable factor, during a controlled time window, could induce epigenetic changes in the germline. The large majority of these experiments investigated changes of DNA methylation at a global, gene-specific, or genome-wide level and will be discussed in this section. A few considered also other types of epigenetic changes such as the sperm microRNA content
[149-151], but, due to their still very small number, they will not be further addressed.

These studies were prompted by the observations of heritable traits unexplained by Mendelian inheritance. However, only a subset of studies showing epigenetic transgenerational effects also provided evidence of potentially heritable epigenetic changes in the exposed gametes. In this review, only those studies that analysed possible DNA methylation changes in the male or female germline of exposed animals have been considered.

Overall, 24 papers were reviewed, 19 reporting studies in mice and 5 in rats. Studies on the possible induction of epigenetic alterations in germ cells were grouped according to the exposure time window: either prenatally, during the critical period of germline differentiation (10 studies), or postnatally, in prepuberal or adult male (12 studies) or female (5 studies) animals. One of the 5 studies on exposure of the female germline was carried out in vitro (Table 2).

From the emerging overview, the research objectives still appear rather sparse: a group of studies evaluated the impact of metabolic changes, due to undernourishment [152], low-protein [153], folate-deficient [154], zinc-deficient [155], obesogenic, and/or diabetogenic diets [149, 156-158]. Other studies investigated the effects of specific compounds, many of which belong to the class of so-called endocrine disrupters, including vinclozolin [159-161], methoxychlor [162], dioxin [163], and bisphenol A [164-166]. The remaining studies deal with a heterogeneous group of potentially epigenetics disrupting agents: particulate air pollution [167], ethanol $[168,169]$, tamoxifen $[170,171]$, fenvalerate [172], and sodium fluoride [173].

Regarding the genomic targets, several studies focused on a few loci, either maternally (Mest, Snrpn, Igf2r, and Peg3) or paternally (H19, Meg3, and Rasgrfl) imprinted (methylated). Other studies evaluated changes of methylation in metabolism-related genes, such as the LPLase, the Ppara, or the Lep gene. One paper included the analysis of methylation of Line-1 repeated sequences [173]. A few studies assessed possible changes of total DNA methylation, whereas the most recent papers report analyses at a genome-wide level. With a few exceptions $[153,160,163,170,173]$, the studies showed some kind of exposure-related effect. Both increase and decrease of methylation levels were reported. As pointed out before, the studies are too scattered and too heterogeneous in the analytical methods to allow drawing general conclusions; however, some hints are emerging, like increased methylation of maternally imprinted and decreased methylation of paternally imprinted genes in the exposed male germline. Interestingly, the few studies on oocyte exposure show an opposite effect of treatment on the same maternally imprinted genes, which seem to respond with a decreased methylation level.

In some studies the impact of exposure on germ cells has been compared with the impact on somatic cells. Depending on the type and time of exposure, some studies showed that the methylation control mechanisms were more robust in the somatic than in the germ cells, as in the case of prenatal treatment with ethanol [168] or methoxychlor [162], but a reversed sensitivity was also observed, as in the case of 


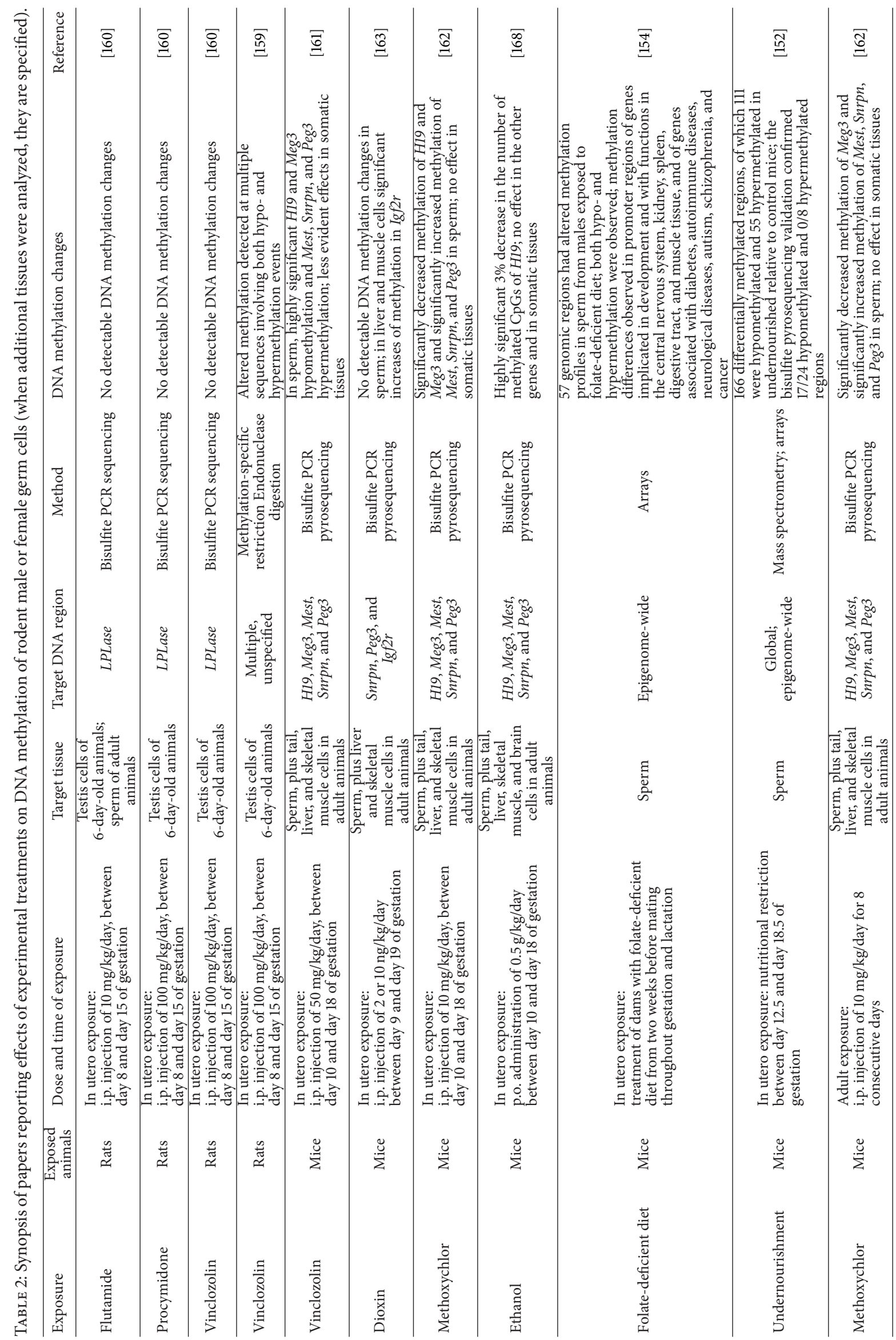




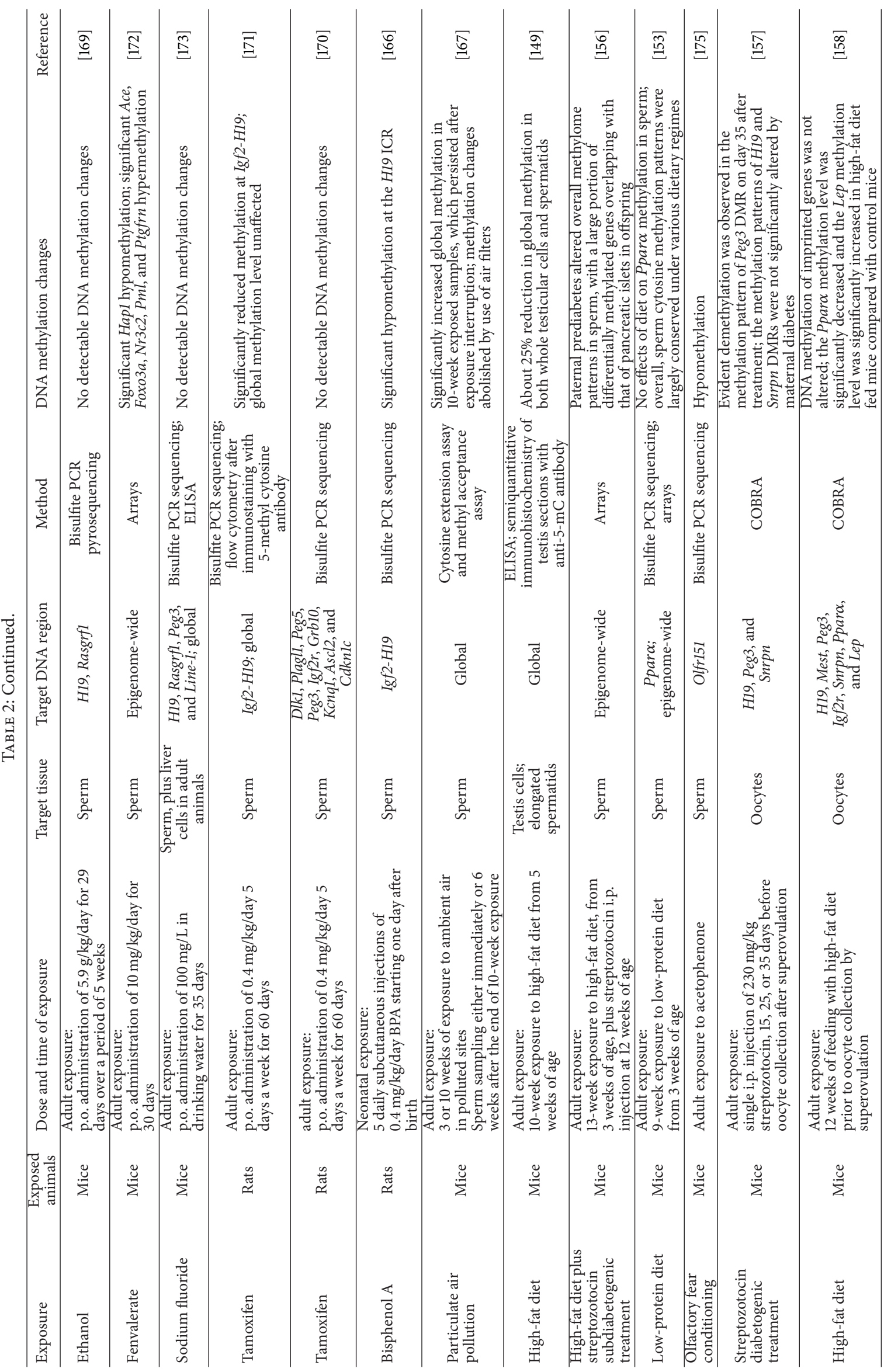




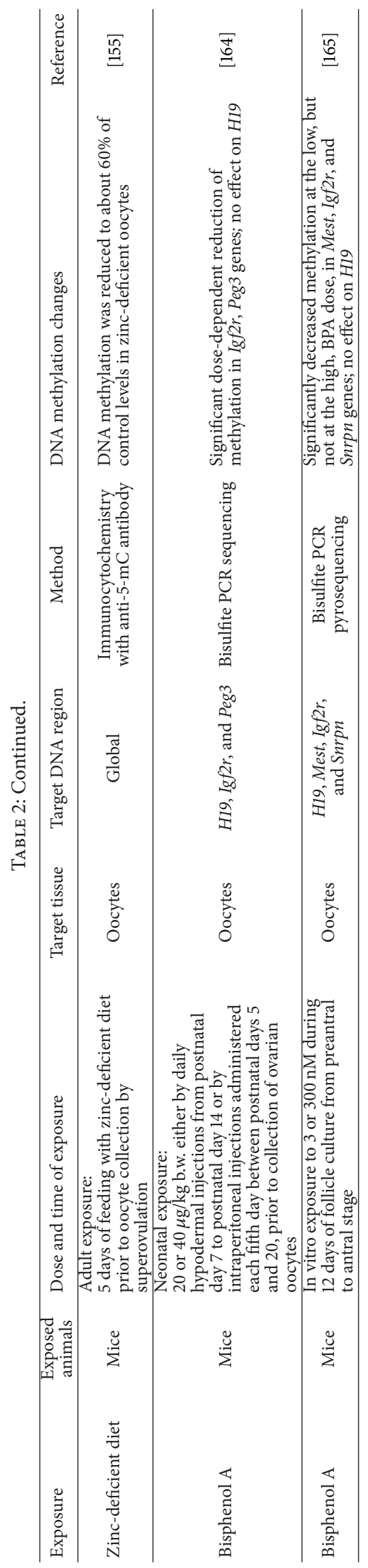


prenatal exposure to dioxin [163]. It is conceivable that each tissue might respond accordingly to its specific developmental program; therefore, studies of exposure during the period of prenatal germline differentiation are especially important for assessing any environmental epigenetic impact on the germline.

The evaluation of an epigenetic impact of exogenous factors on the germline is still in its infancy. A critical issue that has not yet been thoroughly addressed is if and how much the DNA methylation changes have a functional impact on the gene expression level and have any causal role on the male germ cell toxicity that is sometimes induced, as after prenatal vinclozolin [161] or ethanol [168] exposure.

A group of studies aimed mainly to evaluate possible transgenerational consequences of epigenetic alterations in the germline. The simplest hypothesis was that methylation changes in gametes could resist zygotic reprogramming and have functional consequences in the offspring sired by exposed animals.

Indeed, in mice, ethanol exposure in utero was shown to induce $\mathrm{H} 19$ demethylation in sperm of adults, as well as in the brain cells of their offspring, with a good concordance between the CpG demethylation patterns across cell types and generations [168]. In another study testing possible transgenerational effects of tamoxifen in rats [171, 174], the offspring sired by tamoxifen-treated animals showed an increased incidence of embryonic resorptions, and resorbed embryos (but not normal ones) carried methylation errors similar to those detected in the sperm of exposed fathers. In male mice a prediabetic condition closely resembling the metabolic abnormalities of human prediabetes can be induced by high-fat diet and chemical treatment; these mice transmit to their offspring glucose intolerance and insulin resistance [156]. Epigenomic profiling in offspring pancreatic islets identified changes in cytosine methylation at several insulin signaling genes, and these changes correlated with the expression of these genes. The analysis of cytosine methylation profiles in sperm of prediabetic fathers showed several alterations and a large proportion of differentially methylated genes overlapped with that of the offspring pancreatic islets. Bisulfite sequencing of some of these genes in blastocysts showed that they resisted global postfertilization demethylation and largely inherited cytosine methylation from sperm, suggesting that there might be intergenerational transmission of methylation profiles.

However, other studies demonstrated that epigenetic inheritance via the gametes can be more complex than the direct transmission of DNA methylation alterations, and a crosstalk might exist between different levels of epigenetic regulation across generations.

A genome-wide analysis of methylation changes in sperm of mice exposed to a folate-deficient diet showed altered methylation profiles in genes implicated in development, chronic diseases such as cancer, diabetes, autism, and schizophrenia [154]. In the same study, a twofold greater resorption rate and an increased frequency of developmental abnormalities were observed in pregnancies sired by exposed males. Moreover, significant changes in the expression of over 300 genes were detected in the placenta of exposed-animals sired offspring. However, differentially expressed genes in the placenta did not match differentially methylated genes in sperm, suggesting that mechanisms other than DNA methylation might be involved in the transgenerational transmission of epigenetic messages, like sperm histone modifications.

Similarly, in utero undernourishment induced hypomethylation of several genes in sperm, as well as changes of expression of metabolic genes in the brain and liver of late gestation fetuses sired by the exposed animals; interestingly, the genes whose expression was altered in the fetuses mapped close to differentially methylated regions in sperm, although differential methylation was not transgenerationally retained [152]. The authors concluded that "... it is unlikely that these expression changes are directly mediated by altered methylation; rather, the cumulative effects of dysregulated epigenetic patterns earlier in development may yield sustained alterations in chromatin architecture, transcriptional regulatory networks, cell type, or tissue structure."

Postweaning growth delay and decreased methylation at the H19 ICR CTCF binding sites were observed in the offspring of adult mice treated with ethanol, although no decrease of H19 DNA methylation was detectable in the sperm DNA [169]. Methylation was significantly increased in Peg3 and significantly decreased in H19 8-cell embryos sired by male mice treated with sodium fluoride, while no change of methylation was detected in sperm [173]. Increased methylation of a number of imprinted genes, associated with downregulation of transcription, was detected in the resorbing embryos sired by tamoxifen-treated male rats, in spite of the fact that their sperm did not show DNA methylation changes in any of the 9 analyzed imprinted genes [170].

The complexity of the interplay between environmentally sensitive epigenetic markers in sperm and epigenetic modulation of development in the following generation is further illustrated by a recently published report on the transgenerational consequence of paternal exposure to a conditioning olfactory experience [175]. The F1 progeny of conditioned mice reacted just like the fathers with enhanced response, in spite of never being conditioned themselves. The F1 neuroanatomy was also affected. Behavioral sensitivity and neuroanatomical alterations in the nervous system were present also in the IVF-derived F1 generation and persisted until at least the F2 generation. Hypomethylation in specific $\mathrm{CpG}$ islands of the Olfr151 gene encoding for the specific odor receptor was detected in sperm of exposed mice. These findings led the authors "to hypothesize that relative hypomethylation of Olfr151 in F0 sperm may lead to inheritance of the hypomethylated Olfr151 in F1 Main Olfactory Epithelium (MOE) and F1 sperm, creating an inheritance cascade." However, the epigenetic mark was found in the sperm but not in the MOE of F1 mice. Noting that DNA methylation and histone modifications are known to be dependent on each other, the authors suggested that changes in the methylation pattern in sperm DNA might have resulted in histone modifications around the olfactory gene in MOE DNA.

The literature on effects of experimental exposure upon DNA methylation in rodent oocytes is less abundant compared with that on effects induced in sperm. Two papers report undermethylation of maternally imprinted genes in 
oocytes exposed to bisphenol-A either in vivo [164] or in culture [165]. In addition to the challenge posed by working with a little number of cells, experimental studies on femalemediated epigenetic inheritance also face the difficulty of strictly distinguishing a mechanism of epigenetic inheritance via the gametes from other mechanisms of epigenetic inheritance, such as those based on adverse uterine environment or lactation-mediated effects. This issue emerged, for example, in a recent paper [158] showing functional alterations of methylation patterns in the Lep and Ppar $\alpha$ metabolic genes in oocytes of mice treated for 12 weeks with a high-fat diet, as well as in the liver cells of their offspring.

\section{Discussion}

DNA methylation is a life-essential process that modulates gene expression and drives cell differentiation in multicellular organisms. Synergistically with other epigenetic mechanisms, it allows cells and organisms to adapt to external changes, in a timely way that mutational mechanisms could never meet. As such, DNA methylation is unsurprisingly sensitive to external stimuli. At the same time and in contrast to mutations, DNA methylation changes are reversible. This duality poses a challenge to researchers who aim to establish possible links between environmental exposure and epigenetic changes that may have a long-lasting impact on cell function and ultimately on health. Cancer, in all its forms, is the most typical example of a disease associated with aberrant epigenetics, which may be triggered by environmental exposure $[2,176]$, but ample evidence exists where erroneous epigenetic marks also play prominent roles in neurological disorders such as Alzheimer's disease, autoimmune diseases such as rheumatoid arthritis, and cardiovascular diseases, among others [2]. The path of environmental epigenetics will necessarily have to move from initially sparse association studies towards causal relationships supported by biological plausibility.

The plasticity of the human epigenome and the difficulty to sort out major environmental effects from "background noise" can be appreciated from the studies showing a seasonality and weather influence on some DNA methylation biomarkers analyzed in recent human biomonitoring studies $[177,178]$ or the findings of genome-wide analyses that showed an influence of long-term shiftwork on DNA methylation at several loci [179-182]. These latter studies, prompted by the evidence of an association between exposure to light at night, circadian rhythms, and cancer risk, demonstrated indeed methylation changes in many cancer-relevant genes and pathways, but they need to be confirmed by independent replication in larger samples and supported by fundamental mechanistic research, before any firm conclusion can be drawn.

In addition, the fact that interindividual variation in methylation may also be a consequence of DNA sequence polymorphisms that result in methylation quantitative trait loci should not be overlooked. Teh and coworkers [183] have investigated the genotypes and DNA methylomes of 237 neonates and found some 1500 punctuate regions of the methylome highly variable across individuals, termed variably methylated regions (VMRs), against a homogeneous background. The best explanation for $75 \%$ of VMRs was the interaction of genotype with different in utero environments, including maternal smoking, maternal depression, maternal BMI, infant birth weight, gestational age, and birth order. A prevalence of genetic over environmental determinants of interindividual variation of $\mathrm{CpGs}$ methylation has been recently reported in large Scottish and Australian cohorts [184].

Finally, age is expected to be a major variable affecting the DNA methylation profiles in different tissues. In fact, recent studies aimed at exploring the importance of epigenetic changes to the ageing process highlighted age-signatures of DNA methylation [185-187].

One of the problems in drawing an overall pattern from published literature on environmental epigenetic effects is due to the heterogeneity of detection methods and approaches. Several different methods have been developed for DNA methylation analysis and their advantages and drawbacks are discussed in excellent, recent reviews [188-191]. We have witnessed in a short time the passage from the analysis restricted to single specific regions to a global and genomewide scale. Even if, on purely theoretical considerations, the ideal choice would point at a technique able to measure the entire methylome at a single-base-pair resolution in a particular cell system, researchers have to face other issues related to time- and cost-effectiveness and make reasonable compromises with their own scientific questions and the technology available. By and large, cost-affordable technologies are limited in their sensitivity to DNA methylation detection, like those relying on the global immunostaining of the $5-\mathrm{mCs}$ or like pyrosequencing that analyzes only a limited amount of informative cytosines [192, 193]. On the other hand, technologies based on high-resolution methylation arrays [194] are able to measure countless sequences across the genome but are costly and demand sophisticated bioinformatics. The methylation analysis at targeted genes, like those imprinted, involved in some metabolic pathway, or supposedly metastable, and/or in repetitive elements (transposonic or not) is a frequently used approach in environmental epigenetics. Interestingly, it is emerging that repetitive elements, such as Alu and LINE-1, which were initially chosen simply as a proxy of the global methylation level due to their abundance throughout the genome, respond to environmental stress in a sequence-specific manner and have to be considered as separate entities [96, 98, 120, 195]. An international methodological standardization and harmonization effort would contribute to reaching more solid evidence on the epigenetic impact of environmental stressors. It certainly represents a Herculean task as the human haploid DNA methylome contains approximately 30 million CpGs that exist in a methylated, hydroxymethylated, or unmethylated state.

Notwithstanding such difficulties, environmental epigenetics may become a potent concept to fully assess the impact of the exposome on human health [196]. In particular, the notion that, in mammals, tissue differentiation is mainly established during prenatal life, and fundamental DNA methylation changes occur in preimplantation embryo and during gonadal differentiation, may support the hypothesis 
of prenatal origin of adult-onset diseases. To push science forward, epidemiological mother-child cohort studies and maternal exposure assessment will be instrumental.

Also the bases of reproductive health are founded during prenatal life, with primordial germ cell differentiation and gonad development, although the process of gametogenesis will only be completed after puberty. This means that multiple exposure windows must be considered to assess possible environmental effects on the gamete genetic and epigenetic integrity.

The results of the studies in rodents that we have described in the previous section show that DNA methylation in germ cells can be altered by many different kinds of exposure during the fetal as well as the adult life. Still, these studies suffer of some limitations: more data are available on the male than on the female germline, and only few of them carried out the analyses at the most informative genome scale, addressed the functional impact of epigenetic changes on the gene expression level and related cell pathways, and took into consideration dose-effect relationships. Nevertheless, their results are very important because they establish proof of principle demonstration that a variety of exogenous stressors may alter DNA methylation at developmentally important imprinted or metabolic genes.

As a target of environmental exposure, the germline meets a double risk, of compromising the reproduction capacity of the exposed individual and transmitting possible damage to the following generation. Some of the studies in rats and mice indeed showed that treatment induced not only DNA methylation changes in sperm but also phenotype alterations in the sired offspring. These observations are consistent with the notion that DNA methylation profiles of the gametes are not completely reset after fertilization but can be partly transmitted across generations. Actually, few experiments tested this notion in the specific conditions, with some showing apparent inheritance of gamete methylation $[156,168]$, while others not showing the same result [152]. Nevertheless, several authors agree in pointing out that direct transmission of methylation changes is not the only mechanism through which altered sperm methylation might affect the offspring phenotype and that sustained alterations of transcriptional regulatory networks early in development may likely result from a complex interplay between DNA methylation changes, chromatin modifications, and other epigenetic mechanisms. One implication of epigenetic inheritance systems is that they provide a potential mechanism by which parents could transfer information to their offspring about the environment they experienced. In other words, mechanisms exist that could allow organisms to "inform" their progeny about prevailing environmental conditions.

In some of the experimental studies $[162,163,168,169]$, changes of DNA methylation in the germline and somatic cells of exposed animals were compared. On the basis of the few available data, it is not possible to draw any general conclusion, but, much more than for induced genetic changes, it is conceivable that each cell type, with its own transcriptional program, would be specifically affected at an epigenetic level. This consideration poses a problem when data on induced epigenetic changes in the germline of experimental rodents want to be related with human biomonitoring data.

In fact, as previously shown, whereas the database on environmental factors impinging on DNA methylation in human leukocytes is already abundant, very few data exist on the variables affecting DNA methylation in human germ cells, even in the most easily accessible sperm. Acknowledging the limitation of a comparison between two large, but independent, studies, carried out in different cohorts, the increase of LINE-1 methylation reported in blood cells in association with perfluorooctane sulfonate (PFOS) serum level [95], and the lack of an association between PFOS serum level and LINE-1 methylation in sperm [96] exemplifies the difficulty of any extrapolation between somatic and germline environmental epigenetics.

Much more fruitful has been until now the field of male reproductive clinical epigenetics $[35,36]$. The review of data showing DNA methylation and other epigenetic changes in the sperm of subfertile patients was out of the scope of this paper. However, these data are important also for reproductive environmental epigenetics because they seem to indicate a functional significance of DNA methylation changes in the male germline. At the same time, they evidence the need to conduct specific epigenetic analyses on the sperm of men exposed to reproductive toxicants, with the awareness that their PBLs could not surrogate the relevant target cells. Recently, the entire methylome of human sperm has been analyzed at high resolution thanks to the most advanced technologies [127, 197, 198]. While this dataset will be consolidated by repeated analyses and the degree of interindividual variation will be assessed, it will provide an essential reference for future studies on the impact of environmental stressors.

From an overall assessment of the current database on human somatic environmental epigenetics, rodent germline epigenetic toxicological studies, and the most environmentally relevant human reprotoxic agents, a priority list of environmental stressors on which directing future human sperm epigenetic biomonitoring studies might be proposed: dysmetabolism as a consequence of environmental and genetic factors, including their possible interactions, endocrine disrupting compounds, and major lifestyle toxicants like tobacco smoke and alcohol. In addition, emphasis should be on prenatal exposure, and mother child cohorts should be studied more actively. Finally, prospective, long-term, multigeneration follow-up surveys should be possibly set up to take into account grandparental effects.

\section{Abbreviations}

ABCA1: ATP-binding cassette, subfamily A $(\mathrm{ABC} 1)$, member 1

ACE: Angiotensin I-converting enzyme

ACSL3: Acyl-CoA synthetase long-chain family member 3

AHRR: Aryl hydrocarbon receptor repressor

APC: Adenomatous polyposis coli

ASCL2: Achaete-scute family bHLH transcription factor 2 
AXL: $\quad$ AXL receptor tyrosine kinase

BMI: $\quad$ Body mass index

CDKN1C: Cyclin-dependent kinase inhibitor 1C

CNTNAP2: Contactin associated protein-like 2

COBRA: Combined bisulfite restriction analysis

COL1A2: Collagen, type I, alpha 2

CRAT: Carnitine O-acetyltransferase

CTCF: $\quad$ CCCTC-binding factor (zinc finger protein)

CTNNA2: Catenin (cadherin-associated protein), alpha 2

CYP1A1: Cytochrome P450, family 1, subfamily A, polypeptide 1

DAPK: Death-associated protein kinase

DLK1: Delta-like 1 homolog

DMR: Differentially methylated region

DNMT1: DNA (cytosine-5-)-methyl transferase 1

EDs: $\quad$ Endocrine disruptors

ELISA: Enzyme linked immunosorbent assay

F2RL3: Coagulation factor II (thrombin)

receptor-like 3

F3: $\quad$ Coagulation factor III

FOXO3A: Forkhead box O3

FOXP3: $\quad$ Forkhead box transcription factor 3

GC-MS: Gas chromatography-mass spectroscopy

GCR: Glucocorticoid receptor

GFI1: Growth factor independent 1 transcription repressor

GNASAS: GNAS antisense RNA

GPR15: $\quad$ G protein-coupled receptor 15

GRB10: $\quad$ Growth factor receptor-bound protein 10

GSTM1: Glutathione S-transferase mu 1

H19: Imprinted maternally expressed transcript (nonprotein coding)

HAP1: $\quad$ Huntingtin-associated protein 1

HERV: Human endogenous retrovirus

HICl: $\quad$ Hypermethylated in cancer 1

HPLC-MS: High performance liquid chromatography-mass spectrometry

hTERT: Human telomerase reverse transcriptase

ICAM-1: Intercellular adhesion molecule 1

ICR: Imprinting control center

IFN $\gamma$ : Interferon gamma

IGF2: Insulin-like growth factor 2

IGF2R: Insulin-like growth factor 2 receptor

IL-4: Interleukin-4

IL-6: Interleukin-6

IL-10: Interleukin-10

iNOS: Inducible nitric oxide synthase

IVF: $\quad$ In vitro fertilization

KCNK17: Potassium channel, subfamily K, member 17

KCNQ1: Potassium voltage-gated channel, KQT like subfamily, member 1

KLK7: $\quad$ Kallikrein-related peptidase 7

LBW: $\quad$ Low birth weight

LEP: Leptin

LINE-1: Long interspersed nuclear element 1 , retrotransposable element 1

LPLASE: Lysophospholipase

5-mC: 5-methyl cytosine, 5-methyl deoxycytidine
MAGE1: $\quad$ Melanoma antigen family A, 1

MALDI-TOF MS: Matrix-assisted laser desorption ionization time-of-flight mass spectrometry

MEG3: $\quad$ Maternally expressed 3 (nonprotein coding)

MEST:

Mesoderm specific transcript

MLH1:

MYO1G:

MutL homolog 1

NNAT:

NOS1:

NOS2A:

NOS3:

NPY2R:

NR3C2:

OGG1:

OLFR151:

p15:

p16:

p53:

PAHs:

PBL:

PCBs:

PCR:

PEG3:

PEG5:

PEG10:

PFASs:

PGC:

PLAGL1:

PM:

POPs:

PPAR $\alpha$ :

PTGFRN:

Myosin IG

Neuronatin

Nitric oxide synthase 1

Nitric oxide synthase $2 \mathrm{~A}$

Nitric oxide synthase 3

Neuropeptide Y receptor Y2

Nuclear receptor subfamily 3 , group C, member 2

8-Oxoguanine DNA glycosylase 1

Olfactory receptor 151

Cyclin-dependent kinase inhibitor 2B

Cyclin-dependent kinase inhibitor 2A

Tumor protein $\mathrm{p} 53$

Polycyclic aromatic hydrocarbons

Peripheral blood lymphocytes

Polychlorinated biphenyls

Polymerase chain reaction

Paternally expressed 3

Paternally expressed 3 (alias NNAT: neuronatin)

Paternally expressed 10

Perfluoroalkyl substances

Primordial germ cell

Pleomorphic adenoma gene-like 1

Particulate matter

Persistent organic pollutants

Peroxisome proliferator-activated receptor alpha

PTPRO: $\quad$ Protein tyrosine phosphatase, receptor type, $\mathrm{O}$

RASGRF1: Ras protein-specific guanine nucleotide-releasing factor 1

RASSF1A: $\quad$ Ras association (RalGDS/AF-6) domain family member 1

RHBDF1: $\quad$ Rhomboid family member 1

RUNX3: $\quad$ Runt-related transcription factor 3

SEPP1: $\quad$ Selenoprotein P, plasma, 1

SEPW1: $\quad$ Selenoprotein W, 1

SGCE:

SNRPN: $\quad$ Small nuclear ribonucleoprotein

polypeptide $\mathrm{N}$

TLR-2: $\quad$ Toll-like receptor 2

TSP50: $\quad$ Testes-specific protease 50

ZNF132: $\quad$ Zinc finger protein 132.

\section{Conflict of Interests}

The authors declare that there is no conflict of interests. 


\section{Acknowledgment}

The authors wish to apologize to those authors whose contribution was missed by our collections or was not quoted because of space limitations.

\section{References}

[1] C. B. Santos-Rebouças and M. M. G. Pimentel, "Implication of abnormal epigenetic patterns for human diseases," European Journal of Human Genetics, vol. 15, no. 1, pp. 10-17, 2007.

[2] A. Portela and M. Esteller, "Epigenetic modifications and human disease," Nature Biotechnology, vol. 28, no. 10, pp. 1057$1068,2010$.

[3] H. Heyn and M. Esteller, "DNA methylation profiling in the clinic: applications and challenges," Nature Reviews. Genetics, vol. 13, no. 10, pp. 679-692, 2012.

[4] S. Feng, S. E. Jacobsen, and W. Reik, "Epigenetic reprogramming in plant and animal development," Science, vol. 330, no. 6004, pp. 622-627, 2010.

[5] H. Denis, M. N. Ndlovu, and F. Fuks, "Regulation of mammalian DNA methyltransferases: a route to new mechanisms," EMBO Reports, vol. 12, no. 7, pp. 647-656, 2011.

[6] J. A. Hackett and M. A. Surani, "DNA methylation dynamics during the mammalian life cycle," Philosophical Transactions of the Royal Society of London. Series B, Biological sciences, vol. 368, no. 1609, Article ID 20110328, 2013.

[7] S. Seisenberger, J. R. Peat, T. A. Hore, F. Santos, W. Dean, and W. Reik, "Reprogramming DNA methylation in the mammalian life cycle: building and breaking epigenetic barriers," Philosophical transactions of the Royal Society of London, Series B: Biological sciences, vol. 368, no. 1609, Article ID 20110330, 2013.

[8] Z. D. Smith and A. Meissner, "DNA methylation: roles in mammalian development," Nature Reviews Genetics, vol. 14, no. 3, pp. 204-220, 2013.

[9] M. Szyf, "The implications of DNA methylation for toxicology: toward toxicomethylomics, the toxicology of DNA methylation," Toxicological Sciences, vol. 120, no. 2, pp. 235-255, 2011.

[10] J. R. McCarrey, "The epigenome as a target for heritable environmental disruptions of cellular function," Molecular and Cellular Endocrinology, vol. 354, no. 1-2, pp. 9-15, 2012.

[11] V. Bollati and A. Baccarelli, "Environmental epigenetics," Heredity, vol. 105, no. 1, pp. 105-112, 2010.

[12] J. A. Alegría-Torres, A. Baccarelli, and V. Bollati, "Epigenetics and lifestyle," Epigenomics, vol. 3, no. 3, pp. 267-277, 2011.

[13] B. C. Christensen and C. J. Marsit, "Epigenomics in environmental health," Frontiers in Genetics, vol. 2, article 84, 2011.

[14] M. B. Terry, L. Delgado-Cruzata, N. Vin-Raviv, H. C. Wu, and R. M. Santella, "DNA methylation in white blood cells: association with risk factors in epidemiologic studies," Epigenetics, vol. 6, no. 7, pp. 828-837, 2011.

[15] V. K. Cortessis, D. C. Thomas, A. J. Levine et al., "Environmental epigenetics: prospects for studying epigenetic mediation of exposure-response relationships," Human Genetics, vol. 131, no. 10, pp. 1565-1589, 2012.

[16] R. Feil and M. F. Fraga, "Epigenetics and the environment: emerging patterns and implications," Nature Reviews Genetics, vol. 13, no. 2, pp. 97-109, 2012.

[17] L. Hou, X. Zhang, D. Wang, and A. Baccarelli, "Environmental chemical exposures and human epigenetics," International Journal of Epidemiology, vol. 41, no. 1, pp. 79-105, 2012.
[18] U. Lim and M.-A. Song, "Dietary and lifestyle factors of DNA methylation," Methods in Molecular Biology, vol. 863, pp. 359376, 2012.

[19] K. M. Bakulski and M. D. Fallin, "Epigenetic epidemiology: promises for public health research," Environmental and Molecular Mutagenesis, vol. 55, no. 3, pp. 171-183, 2014.

[20] H. H. Burris and A. A. Baccarelli, "Environmental epigenetics: from novelty to scientific discipline," Journal of Applied Toxicology, vol. 34, no. 2, pp. 113-116, 2014.

[21] I. Cantone and A. G. Fisher, "Epigenetic programming and reprogramming during development," Nature Structural and Molecular Biology, vol. 20, no. 3, pp. 282-289, 2013.

[22] S. Seisenberger, J. R. Peat, and W. Reik, "Conceptual links between DNA methylation reprogramming in the early embryo and primordial germ cells," Current Opinion in Cell Biology, vol. 25, no. 3, pp. 281-288, 2013.

[23] G. Kelsey and R. Feil, "New insights into establishment and maintenance of DNA methylation imprints in mammals," Philosophical Transactions of the Royal Society of London, Series B: Biological Sciences, vol. 368, no. 1609, Article ID 20110336, 2013.

[24] D. J. P. Barker, P. D. Gluckman, K. M. Godfrey, J. E. Harding, J. A. Owens, and J. S. Robinson, "Fetal nutrition and cardiovascular disease in adult life," The Lancet, vol. 341, no. 8850, pp. 938-941, 1993.

[25] P. Dominguez-Salas, S. E. Cox, A. M. Prentice, B. J. Hennig, and S. E. Moore, "Maternal nutritional status, $\mathrm{C}_{1}$ metabolism and offspring DNA methylation: a review of current evidence in human subjects," Proceedings of the Nutrition Society, vol. 71, no. 1, pp. 154-165, 2012.

[26] M. Pembrey, R. Saffery, L. O. Bygren, and Network in Epigenetic Epidemiology, "Human transgenerational responses to earlylife experience: potential impact on development, health and biomedical research," Journal of Medical Genetics, vol. 51, no. 9, pp. 563-572, 2014.

[27] A. Juul, K. Almstrup, A. M. Andersson et al., "Possible fetal determinants of male infertility," Nature Reviews Endocrinology, vol. 10, no. 9, pp. 553-562, 2014.

[28] R. M. Sharpe, "Environmental/lifestyle effects on spermatogenesis," Philosophical Transactions of the Royal Society B: Biological Sciences, vol. 365, no. 1546, pp. 1697-1712, 2010.

[29] J. D. Meeker, "Exposure to environmental endocrine disrupting compounds and men's health," Maturitas, vol. 66, no. 3, pp. 236241, 2010.

[30] A. Giwercman and Y. L. Giwercman, "Environmental factors and testicular function," Best Practice and Research: Clinical Endocrinology and Metabolism, vol. 25, no. 2, pp. 391-402, 2011.

[31] J. P. Bonde and A. Giwercman, "Environmental xenobiotics and male reproductive health," Asian Journal of Andrology, vol. 16, no. 1, pp. 3-4, 2014.

[32] A. Vested, A. Giwercman, J. P. Bonde, and G. Toft, "Persistent organic pollutants and male reproductive health," Asian Journal of Andrology, vol. 16, no. 1, pp. 71-80, 2014.

[33] J. Del Mazo, M. A. Brieño-Enríquez, J. García-López, L. A. López-Fernández, and M. De Felici, "Endocrine disruptors, gene deregulation and male germ cell tumors," International Journal of Developmental Biology, vol. 57, no. 2-4, pp. 225-239, 2013.

[34] K. Singh and D. Jaiswal, "One-carbon metabolism, spermatogenesis, and male infertility," Reproductive Sciences, vol. 20, no. 6, pp. 622-630, 2013. 
[35] C. C. Boissonnas, P. Jouannet, and H. Jammes, "Epigenetic disorders and male subfertility," Fertility and Sterility, vol. 99, no. 3, pp. 624-631, 2013.

[36] R. Kläver and J. Gromoll, "Bringing epigenetics into the diagnostics of the andrology laboratory: challenges and perspectives," Asian Journal of Andrology, vol. 16, no. 5, pp. 669-674, 2014.

[37] J. Borgel, S. Guibert, Y. Li et al., "Targets and dynamics of promoter DNA methylation during early mouse development," Nature Genetics, vol. 42, no. 12, pp. 1093-1100, 2010.

[38] L. Daxinger and E. Whitelaw, "Understanding transgenerational epigenetic inheritance via the gametes in mammals," Nature Reviews Genetics, vol. 13, no. 2, pp. 153-162, 2012.

[39] J. M. Trasler, "Epigenetics in spermatogenesis," Molecular and Cellular Endocrinology, vol. 306, no. 1-2, pp. 33-36, 2009.

[40] D. T. Carrell, "Epigenetics of the male gamete," Fertility and Sterility, vol. 97, no. 2, pp. 267-274, 2012.

[41] R. Guerrero-Preston, J. Herbstman, and L. R. Goldman, "Epigenomic biomonitors: global DNA hypomethylation as a biodosimeter of life-long environmental exposures," Epigenomics, vol. 3, no. 1, pp. 1-5, 2011.

[42] R. R. Kanherkar, N. Bhatia-Dey, and A. B. Csoka, "Epigenetics across the human lifespan," Frontiers in Cell and Developmental Biology, vol. 2, article 49, 2014.

[43] P. D. Ray, A. Yosim, and R. C. Fry, "Incorporating epigenetic data into the risk assessment process for the toxic metals arsenic, cadmium, chromium, lead, and mercury: strategies and challenges," Frontiers in Genetics, vol. 5, article 201, 2014.

[44] K. A. Bailey and R. C. Fry, "Arsenic-associated changes to the epigenome: what are the functional consequences?" Current Environmental Health Reports, vol. 1, no. 1, pp. 22-34, 2014.

[45] J. R. Pilsner, X. Liu, H. Ahsan et al., "Genomic methylation of peripheral blood leukocyte DNA: influences of arsenic and folate in Bangladeshi adults," The American Journal of Clinical Nutrition, vol. 86, no. 4, pp. 1179-1186, 2007.

[46] S. Majumdar, S. Chanda, B. Ganguli, D. N. G. Mazumder, S. Lahiri, and U. B. Dasgupta, "Arsenic exposure induces genomic hypermethylation," Environmental Toxicology, vol. 25, no. 3, pp. 315-318, 2010.

[47] M. M. Niedzwiecki, M. N. Hall, X. Liu et al., "A dose-response study of arsenic exposure and global methylation of peripheral blood mononuclear cell DNA in Bangladeshi adults," Environmental Health Perspectives, vol. 121, no. 11-12, pp. 1306-1312, 2013.

[48] S. Chanda, U. B. Dasgupta, D. Guhamazumder et al., "DNA hypermethylation of promoter of gene p53 and p16 in arsenicexposed people with and without malignancy," Toxicological Sciences, vol. 89, no. 2, pp. 431-437, 2006.

[49] A.-H. Zhang, H.-H. Bin, X.-L. Pan, and X.-G. Xi, "Analysis of p16 gene mutation, deletion and methylation in patients with arseniasis produced by indoor unventilated-stove coal usage in Guizhou, China," Journal of Toxicology and Environmental Health, Part A, vol. 70, no. 11, pp. 970-975, 2007.

[50] L. Smeester, J. E. Rager, K. A. Bailey et al., "Epigenetic changes in individuals with arsenicosis," Chemical Research in Toxicology, vol. 24, no. 2, pp. 165-167, 2011.

[51] M. B. Hossain, M. Vahter, G. Concha, and K. Broberg, "Environmental arsenic exposure and DNA methylation of the tumor suppressor gene p16 and the DNA repair gene MLH1: effect of arsenic metabolism and genotype," Metallomics, vol. 4, no. 11, pp. 1167-1175, 2012.
[52] W.-T. Chen, W.-C. Hung, W.-Y. Kang, Y.-C. Huang, and C.-Y. Chai, "Urothelial carcinomas arising in arsenic-contaminated areas are associated with hypermethylation of the gene promoter of the death-associated protein kinase," Histopathology, vol. 51, no. 6, pp. 785-792, 2007.

[53] W. J. Seow, M. L. Kile, A. A. Baccarelli et al., "Epigenomewide DNA methylation changes with development of arsenicinduced skin lesions in Bangladesh: a case-control follow-up study," Environmental and Molecular Mutagenesis, vol. 55, no. 6, pp. 449-456, 2014.

[54] T.-Y. Yang, L.-I. Hsu, A. W. Chiu et al., "Comparison of genomewide DNA methylation in urothelial carcinomas of patients with and without arsenic exposure," Environmental Research, vol. 128, pp. 57-63, 2014.

[55] M. L. Kile, A. Baccarelli, E. Hoffman et al., "Prenatal arsenic exposure and DNA methylation in maternal and umbilical cord blood leukocytes," Environmental Health Perspectives, vol. 120, no. 7, pp. 1061-1066, 2012.

[56] M. L. Kile, E. A. Houseman, A. A. Baccarelli et al., "Effect of prenatal arsenic exposure on DNA methylation and leukocyte subpopulations in cord blood," Epigenetics, vol. 9, no. 5, pp. 774782, 2014.

[57] J. R. Pilsner, M. N. Hall, X. Liu et al., "Influence of prenatal arsenic exposure and newborn sex on global methylation of cord blood DNA," PLoS ONE, vol. 7, no. 5, Article ID e37147, 2012.

[58] P. Intarasunanont, P. Navasumrit, S. Waraprasit et al., "Effects of arsenic exposure on DNA methylation in cord blood samples from newborn babies and in a human lymphoblast cell line," Environmental Health: A Global Access Science Source, vol. 11, no. 1, article 31, 2012.

[59] D. C. Koestler, M. Avissar-Whiting, E. A. Houseman, M. R. Karagas, and C. J. Marsit, "Differential DNA methylation in umbilical cord blood of infants exposed to low levels of arsenic in utero," Environmental Health Perspectives, vol. 121, no. 8, pp. 971-977, 2013.

[60] D. Rojas, J. E. Rager, L. Smeester et al., "Prenatal arsenic exposure and the epigenome: identifying sites of 5-methylcytosine alterations that predict functional changes in gene expression in newborn cord blood and subsequent birth outcomes," Toxicological Sciences, vol. 143, no. 1, pp. 97-106, 2015.

[61] T.-C. Wang, Y.-S. Song, H. Wang et al., "Oxidative DNA damage and global DNA hypomethylation are related to folate deficiency in chromate manufacturing workers," Journal of Hazardous Materials, vol. 213-214, pp. 440-446, 2012.

[62] C. W. Hanna, M. S. Bloom, W. P. Robinson et al., "DNA methylation changes in whole blood is associated with exposure to the environmental contaminants, mercury, lead, cadmium and bisphenol $\mathrm{A}$, in women undergoing ovarian stimulation for IVF," Human Reproduction, vol. 27, no. 5, pp. 1401-1410, 2012.

[63] J. M. Goodrich, N. Basu, A. Franzblau, and D. C. Dolinoy, "Mercury biomarkers and DNA methylation among michigan dental professionals," Environmental and Molecular Mutagenesis, vol. 54, no. 3, pp. 195-203, 2013.

[64] R. O. Wright, J. Schwartz, R. J. Wright et al., "Biomarkers of lead exposure and DNA methylation within retrotransposons," Environmental Health Perspectives, vol. 118, no. 6, pp. 790-795, 2010.

[65] L. Kovatsi, E. Georgiou, A. Ioannou et al., "P16 promoter methylation in $\mathrm{Pb}^{2+}$-exposed individuals," Clinical Toxicology, vol. 48, no. 2, pp. 124-128, 2010. 
[66] M. B. Hossain, M. Vahter, G. Concha, and K. Broberg, "Lowlevel environmental cadmium exposure is associated with DNA hypomethylation in Argentinean women," Environmental Health Perspectives, vol. 120, no. 6, pp. 879-884, 2012.

[67] J. R. Pilsner, M. N. Hall, X. Liu et al., "Associations of plasma selenium with arsenic and genomic methylation of leukocyte DNA in bangladesh," Environmental Health Perspectives, vol. 119, no. 1, pp. 113-118, 2011.

[68] A. P. Sanders, L. Smeester, D. Rojas et al., "Cadmium exposure and the epigenome: exposure-associated patterns of DNA methylation in leukocytes from mother-baby pairs," Epigenetics, vol. 9, no. 2, pp. 212-221, 2014.

[69] H. Ji and G. K. Khurana Hershey, "Genetic and epigenetic influence on the response to environmental particulate matter," Journal of Allergy and Clinical Immunology, vol. 129, no. 1, pp. 33-41, 2012.

[70] S. De Prins, G. Koppen, G. Jacobs et al., "Influence of ambient air pollution on global DNA methylation in healthy adults: a seasonal follow-up," Environment International, vol. 59, pp. 418424, 2013.

[71] A. Baccarelli, R. O. Wright, V. Bollati et al., "Rapid DNA methylation changes after exposure to traffic particles," The American Journal of Respiratory and Critical Care Medicine, vol. 179, no. 7, pp. 572-578, 2009.

[72] J. Madrigano, A. Baccarelli, M. A. Mittleman et al., "Prolonged exposure to particulate pollution, genes associated with glutathione pathways, and DNA methylation in a cohort of older men," Environmental Health Perspectives, vol. 119, no. 7, pp. 977982, 2011.

[73] M. A. Bind, J. Lepeule, A. Zanobetti et al., "Air pollution and gene-specific methylation in the Normative Aging Study: association, effect modification, and mediation analysis," Epigenetics, vol. 9, no. 3, pp. 448-458, 2014.

[74] J. Lepeule, M.-A. C. Bind, A. A. Baccarelli et al., "Epigenetic influences on associations between air pollutants and lung function in elderly men: the normative aging study," Environmental Health Perspectives, vol. 122, no. 6, pp. 566-572, 2014.

[75] K. Nadeau, C. McDonald-Hyman, E. M. Noth et al., "Ambient air pollution impairs regulatory T-cell function in asthma," Journal of Allergy and Clinical Immunology, vol. 126, no. 4, pp. 845.e10-852.e10, 2010.

[76] C. V. Breton, M. T. Salam, X. Wang, H.-M. Byun, K. D. Siegmund, and F. D. Gilliland, "Particulate matter, DNA methylation in nitric oxide synthase, and childhood respiratory disease," Environmental Health Perspectives, vol.120, no. 9, pp. 1320-1326, 2012.

[77] M. T. Salam, H. M. Byun, F. Lurmann et al., "Genetic and epigenetic variations in inducible nitric oxide synthase promoter, particulate pollution, and exhaled nitric oxide levels in children," Journal of Allergy and Clinical Immunology, vol. 129, no. 1, pp. 232.e7-239.e7, 2012.

[78] J. B. Herbstman, D. Tang, D. Zhu et al., "Prenatal exposure to polycyclic aromatic hydrocarbons, benzo[a]pyrene-DNA adducts, and genomic DNA methylation in cord blood," Environmental Health Perspectives, vol. 120, no. 5, pp. 733-738, 2012.

[79] F. Perera, W.-Y. Tang, J. Herbstman et al., "Relation of DNA methylation of $5^{\prime}-\mathrm{CpG}$ island of ACSL3 to transplacental exposure to airborne polycyclic aromatic hydrocarbons and childhood asthma," PLoS ONE, vol. 4, no. 2, Article ID e4488, 2009.

[80] W.-Y. Tang, L. Levin, G. Talaska et al., "Maternal exposure to polycyclic aromatic hydrocarbons and $5 /-\mathrm{CpG}$ methylation of interferon- $\gamma$ in cord white blood cells," Environmental Health Perspectives, vol. 120, no. 8, pp. 1195-1200, 2012.

[81] L. Tarantini, M. Bonzini, P. Apostoli et al., "Effects of particulate matter on genomic DNA methylation content and iNOS promoter methylation," Environmental Health Perspectives, vol. 117 , no. 2, pp. 217-222, 2009.

[82] L. Hou, X. Zhang, L. Tarantini et al., "Ambient PM exposure and DNA methylation in tumor suppressor genes: a cross-sectional study," Particle and Fibre Toxicology, vol. 8, article 25, 2011.

[83] L. Dioni, M. Hoxha, F. Nordio et al., "Effects of short-term exposure to inhalable particulate matter on telomere length, telomerase expression, and telomerase methylation in steel workers," Environmental Health Perspectives, vol. 119, no. 5, pp. 622-627, 2011.

[84] S. Pavanello, V. Bollati, A. C. Pesatori et al., "Global and gene-specific promoter methylation changes are related to anti-B[a]PDE-DNA adduct levels and influence micronuclei levels in polycyclic aromatic hydrocarbon-exposed individuals," International Journal of Cancer, vol. 125, no. 7, pp. 1692-1697, 2009.

[85] L. Guo, H.-M. Byun, J. Zhong et al., "Effects of short-term exposure to inhalable particulate matter on DNA methylation of tandem repeats," Environmental and Molecular Mutagenesis, vol. 55, no. 4, pp. 322-335, 2014.

[86] L. Hou, X. Zhang, Y. Zheng et al., "Altered methylation in tandem repeat element and elemental component levels in inhalable air particles," Environmental and Molecular Mutagenesis, vol. 55, no. 3, pp. 256-265, 2014.

[87] H.-M. Byun, V. Motta, T. Panni et al., "Evolutionary age of repetitive element subfamilies and sensitivity of DNA methylation to airborne pollutants," Particle and Fibre Toxicology, vol. 10, no. 1, article 28, 2013.

[88] M. Peluso, V. Bollati, A. Munnia et al., "DNA methylation differences in exposed workers and nearby residents of the Ma Ta phut industrial estate, rayong, Thailand," International Journal of Epidemiology, vol. 41, no. 6, pp. 1753-1760, 2012.

[89] V. Bollati, A. Baccarelli, L. Hou et al., "Changes in DNA methylation patterns in subjects exposed to low-dose benzene," Cancer Research, vol. 67, no. 3, pp. 876-880, 2007.

[90] S. Fustinoni, F. Rossella, E. Polledri et al., "Global DNA methylation and low-level exposure to benzene," La Medicina del Lavoro, vol. 103, no. 2, pp. 84-95, 2012.

[91] W. J. Seow, A. C. Pesatori, E. Dimont et al., "Urinary benzene biomarkers and DNA methylation in Bulgarian petrochemical workers: study findings and comparison of linear and beta regression models," PLoS ONE, vol. 7, no. 12, Article ID e50471, 2012.

[92] J. A. Rusiecki, A. Baccarelli, V. Bollati, L. Tarantini, L. E. Moore, and E. C. Bonefeld-Jorgensen, "Global DNA hypomethylation is associated with high serum-persistent organic pollutants in Greenlandic inuit," Environmental Health Perspectives, vol. 116, no. 11, pp. 1547-1552, 2008.

[93] K.-Y. Kim, D.-S. Kim, S.-K. Lee et al., "Association of lowdose exposure to persistent organic pollutants with global DNA hypomethylation in healthy Koreans," Environmental Health Perspectives, vol. 118, no. 3, pp. 370-374, 2010.

[94] J. H. Kim, L. S. Rozek, A. S. Soliman et al., "Bisphenol Aassociated epigenomic changes in prepubescent girls: a crosssectional study in Gharbiah, Egypt," Environmental Health: A Global Access Science Source, vol. 12, article 33, 2013. 
[95] D. J. Watkins, G. A. Wellenius, R. A. Butler, S. M. Bartell, T. Fletcher, and K. T. Kelsey, "Associations between serum perfluoroalkyl acids and LINE-1 DNA methylation," Environment International, vol. 63, pp. 71-76, 2014.

[96] G. Leter, C. Consales, P. Eleuteri et al., "Exposure to perfluoroalkyl substances and sperm DNA global methylation in arctic and european populations," Environmental and Molecular Mutagenesis, vol. 55, no. 7, pp. 591-600, 2014.

[97] R. Guerrero-Preston, L. R. Goldman, P. Brebi-Mieville et al., "Global DNA hypomethylation is associated with in utero exposure to cotinine and perfluorinated alkyl compounds," Epigenetics, vol. 5, no. 6, pp. 539-546, 2010.

[98] K. Huen, P. Yousefi, A. Bradman et al., "Effects of age, sex, and persistent organic pollutants on DNA methylation in children," Environmental and Molecular Mutagenesis, vol. 55, no. 3, pp. 209-222, 2014.

[99] N. Vilahur, M. Bustamante, H. Byun et al., "Prenatal exposure to mixtures of xenoestrogens and repetitive element DNA methylation changes in human placenta," Environment International, vol. 71, pp. 81-87, 2014.

[100] A. C. Vidal, S. K. Murphy, A. P. Murtha et al., "Associations between antibiotic exposure during pregnancy, birth weight and aberrant methylation at imprinted genes among offspring," International Journal of Obesity, vol. 37, no. 7, pp. 907-913, 2013.

[101] V. S. Knopik, M. A. MaCcani, S. Francazio, and J. E. McGeary, "The epigenetics of maternal cigarette smoking during pregnancy and effects on child development," Development and Psychopathology, vol. 24, no. 4, pp. 1377-1390, 2012.

[102] K. W. K. Lee and Z. Pausova, "Cigarette smoking and DNA methylation," Frontiers in Genetics, vol. 4, article 132, 2013.

[103] L. P. Breitling, R. Yang, B. Korn, B. Burwinkel, and H. Brenner, "Tobacco-smoking-related differential DNA methylation: 27K discovery and replication," American Journal of Human Genetics, vol. 88, no. 4, pp. 450-457, 2011.

[104] L. P. Breitling, K. Salzmann, D. Rothenbacher, B. Burwinkel, and H. Brenner, "Smoking, F2RL3 methylation, and prognosis in stable coronary heart disease," European Heart Journal, vol. 33, no. 22, pp. 2841-2848, 2012.

[105] N. S. Shenker, S. Polidoro, K. van Veldhoven et al., "Epigenomewide association study in the European Prospective Investigation into Cancer and Nutrition (EPIC-Turin) identifies novel genetic loci associated with smoking," Human Molecular Genetics, vol. 22, no. 5, pp. 843-851, 2013.

[106] Y. Zhang, R. Yang, B. Burwinkel, L. P. Breitling, and H. Brenner, "F2RL3 methylation as a biomarker of current and lifetime smoking exposures," Environmental Health Perspectives, vol. 122, no. 2, pp. 131-137, 2014.

[107] Y. Zhang, R. Yang, B. Burwinkel et al., "F2RL3 methylation in blood DNA is a strong predictor of mortality," International Journal of Epidemiology, vol. 43, no. 4, pp. 1215-1225, 2014.

[108] M. M. Monick, S. R. H. Beach, J. Plume et al., "Coordinated changes in AHRR methylation in lymphoblasts and pulmonary macrophages from smokers," American Journal of Medical Genetics, Part B: Neuropsychiatric Genetics, vol. 159, no. 2, pp. 141-151, 2012.

[109] R. A. Philibert, S. R. H. Beach, and G. H. Brody, "Demethylation of the aryl hydrocarbon receptor repressor as a biomarker for nascent smokers," Epigenetics, vol. 7, no. 11, pp. 1331-1338, 2012.

[110] R. A. Philibert, S. R. H. Beach, M.-K. Lei, and G. H. Brody, "Changes in DNA methylation at the aryl hydrocarbon receptor repressor may be a new biomarker for smoking," Clinical Epigenetics, vol. 5, no. 1, article 19, 2013.
[111] N. S. Shenker, P. M. Ueland, S. Polidoro et al., "DNA methylation as a long-term biomarker of exposure to tobacco smoke," Epidemiology, vol. 24, no. 5, pp. 712-716, 2013.

[112] M. V. Dogan, B. Shields, C. Cutrona et al., "The effect of smoking on DNA methylation of peripheral blood mononuclear cells from African American women," BMC Genomics, vol. 15, no. 1, article 151, 2014.

[113] C. V. Breton, H.-M. Byun, M. Wenten, F. Pan, A. Yang, and F. D. Gilliland, "Prenatal tobacco smoke exposure affects global and gene-specific DNA methylation," The American Journal of Respiratory and Critical Care Medicine, vol. 180, no. 5, pp. 462467, 2009.

[114] C. V. Breton, M. T. Salam, and F. D. Gilliland, "Heritability and role for the environment in DNA methylation in AXL receptor tyrosine kinase," Epigenetics, vol. 6, no. 7, pp. 895-898, 2011.

[115] C. V. Breton, K. D. Siegmund, B. R. Joubert et al., "Prenatal tobacco smoke exposure is associated with childhood DNA CpG methylation," PLoS ONE, vol. 9, no. 6, Article ID e99716, 2014.

[116] M. Suter, A. Abramovici, L. Showalter et al., "In utero tobacco exposure epigenetically modifies placental CYP1A1 expression," Metabolism, vol. 59, no. 10, pp. 1481-1490, 2010.

[117] M. Suter, J. Ma, A. Harris et al., "Maternal tobacco use modestly alters correlated epigenome-wide placental DNA methylation and gene expression," Epigenetics, vol. 6, no. 11, pp. 1284-1294, 2011.

[118] B. R. Joubert, S. E. Håberg, R. M. Nilsen et al., “ $450 \mathrm{~K}$ epigenome-wide scan identifies differential DNA methylation in newborns related to maternal smoking during pregnancy," Environmental Health Perspectives, vol. 120, no. 10, pp. 14251431, 2012.

[119] S. K. Murphy, A. Adigun, Z. Huang et al., "Gender-specific methylation differences in relation to prenatal exposure to cigarette smoke," Gene, vol. 494, no. 1, pp. 36-43, 2012.

[120] C. S. Wilhelm-Benartzi, E. A. Houseman, M. A. Maccani et al., "In utero exposures, infant growth, and DNA methylation of repetitive elements and developmentally related genes in human placenta," Environmental Health Perspectives, vol. 120, no. 2, pp. 296-302, 2012.

[121] J. Z. J. Maccani, D. C. Koestler, E. A. Houseman, C. J. Marsit, and K. T. Kelsey, "Placental DNA methylation alterations associated with maternal tobacco smoking at the RUNX3 gene are also associated with gestational age," Epigenomics, vol. 5, no. 6, pp. 619-630, 2013.

[122] K. W. Lee, R. Richmond, P. Hu et al., "Prenatal exposure to maternal cigarette smoking and DNA methylation: epigenomewide association in a discovery sample of adolescents and replication in an independent cohort at birth through 17 years of age," Environmental Health Perspectives, vol. 123, no. 2, pp. 193-199, 2015.

[123] A. Soubry, C. Hoyo, R. L. Jirtle, and S. K. Murphy, "A paternal environmental legacy: evidence for epigenetic inheritance through the male germ line," BioEssays, vol. 36, no. 4, pp. 359371, 2014.

[124] A. Soubry, J. M. Schildkraut, A. Murtha et al., "Paternal obesity is associated with IGF2 hypomethylation in newborns: results from a Newborn Epigenetics Study (NEST) cohort," BMC Medicine, vol. 11, no. 1, article 29, 2013.

[125] A. Soubry, S. K. Murphy, F. Wang et al., "Newborns of obese parents have altered DNA methylation patterns at imprinted genes," International Journal of Obesity, vol. 39, pp. 650-657, 2015. 
[126] T. G. Jenkins, K. I. Aston, B. R. Cairns, and D. T. Carrell, "Paternal aging and associated intraindividual alterations of global sperm 5-methylcytosine and 5-hydroxymethylcytosine levels," Fertility and Sterility, vol. 100, no. 4, pp. 945-951, 2013.

[127] T. G. Jenkins, K. I. Aston, C. Pflueger, B. R. Cairns, D. T. Carrell, and J. M. Greally, "Age-associated sperm DNA methylation alterations: possible implications in offspring disease susceptibility," PLoS Genetics, vol. 10, no. 7, Article ID e1004458, 2014.

[128] C. Consales, G. Leter, J. P. Bonde et al., "Indices of methylation in sperm DNA from fertile men differ between distinct geographical regions," Human Reproduction, vol. 29, no. 9, pp. 2065-2072, 2014

[129] D. Kumar, S. R. Salian, G. Kalthur et al., "Semen abnormalities, sperm DNA damage and global hypermethylation in health workers occupationally exposed to ionizing radiation," PLoS ONE, vol. 8, no. 7, Article ID e69927, 2013.

[130] D. M. Bielawski, F. M. Zaher, D. M. Svinarich, and E. L. Abel, "Paternal alcohol exposure affects sperm cytosine methyltransferase messenger RNA levels," Alcoholism: Clinical and Experimental Research, vol. 26, no. 3, pp. 347-351, 2002.

[131] L. A. Ouko, K. Shantikumar, J. Knezovich, P. Haycock, D. J. Schnugh, and M. Ramsay, "Effect of alcohol consumption on CpG methylation in the differentially methylated regions of $\mathrm{H} 19$ and IG-DMR in male gametes-implications for fetal alcohol spectrum disorders," Alcoholism: Clinical and Experimental Research, vol. 33, no. 9, pp. 1615-1627, 2009.

[132] M. Lane, R. L. Robker, and S. A. Robertson, "Parenting from before conception," Science, vol. 345, no. 6198, pp. 756-760, 2014.

[133] X. Liu, Q. Chen, H.-J. Tsai et al., "Maternal preconception body mass index and offspring cord blood DNA methylation: exploration of early life origins of disease," Environmental and Molecular Mutagenesis, vol. 55, no. 3, pp. 223-230, 2014.

[134] L. H. Lumey, M. B. Terry, L. Delgado-Cruzata et al., "Adult global DNA methylation in relation to pre-natal nutrition," International Journal of Epidemiology, vol. 41, no. 1, pp. 116-123, 2012.

[135] B. T. Heijmans, E. W. Tobi, A. D. Stein et al., "Persistent epigenetic differences associated with prenatal exposure to famine in humans," Proceedings of the National Academy of Sciences of the United States of America, vol. 105, no. 44, pp. 17046-17049, 2008.

[136] B. T. Heijmans, E. W. Tobi, L. H. Lumey, and P. E. Slagboom, "The epigenome: archive of the prenatal environment," Epigenetics, vol. 4, no. 8, pp. 526-531, 2009.

[137] E. W. Tobi, L. H. Lumey, R. P. Talens et al., "DNA methylation differences after exposure to prenatal famine are common and timing- and sex-specific," Human Molecular Genetics, vol. 18, no. 21, pp. 4046-4053, 2009.

[138] E. W. Tobi, B. T. Heijmans, D. Kremer et al., "DNA methylation of IGF2, GNASAS, INSIGF and LEP and being born small for gestational age," Epigenetics, vol. 6, no. 2, pp. 171-176, 2011.

[139] E. W. Tobi, P. E. Slagboom, J. van Dongen et al., "Prenatal famine and genetic variation are independently and additively associated with dna methylation at regulatory loci within IGF2/H19," PLoS ONE, vol. 7, no. 5, Article ID e37933, 2012.

[140] E. W. Tobi, J. J. Goeman, R. Monajemi et al., "DNA methylation signatures link prenatal famine exposure to growth and metabolism," Nature Communications, vol. 5, article 5592, 2014.

[141] C. Hoyo, A. P. Murtha, J. M. Schildkraut et al., "Methylation variation at IGF2 differentially methylated regions and maternal folic acid use before and during pregnancy," Epigenetics, vol. 6, no. 7, pp. 928-936, 2011.

[142] P. Haggarty, G. Hoad, D. M. Campbell, G. W. Horgan, C. Piyathilake, and G. McNeill, "Folate in pregnancy and imprinted gene and repeat element methylation in the offspring," American Journal of Clinical Nutrition, vol. 97, no. 1, pp. 94-99, 2013.

[143] C. E. Boeke, A. Baccarelli, K. P. Kleinman et al., "Gestational intake of methyl donors and global LINE-1 DNA methylation in maternal and cord blood: prospective results from a folatereplete population," Epigenetics, vol. 7, no. 3, pp. 253-260, 2012.

[144] R. A. Waterland, R. Kellermayer, E. Laritsky et al., "Season of conception in rural gambia affects DNA methylation at putative human metastable epialleles," PLoS Genetics, vol. 6, no. 12, Article ID e1001252, 2010.

[145] P. Dominguez-Salas, S. E. Moore, M. S. Baker et al., "Maternal nutrition at conception modulates DNA methylation of human metastable epialleles," Nature Communications, vol. 5, article 3746, 2014.

[146] R. A. Harris, D. Nagy-Szakal, and R. Kellermayer, "Human metastable epiallele candidates link to common disorders," Epigenetics, vol. 8, no. 2, pp. 157-163, 2013.

[147] Y. Liu, S. K. Murphy, A. P. Murtha et al., "Depression in pregnancy, infant birth weight and DNA methylation of imprint regulatory elements," Epigenetics, vol. 7, no. 7, pp. 735-746, 2012.

[148] L. Cao-Lei, R. Massart, M. J. Suderman et al., "DNA methylation signatures triggered by prenatal maternal stress exposure to a natural disaster: project ice storm," PLoS ONE, vol. 9, no. 9, Article ID e107653, 2014.

[149] T. Fullston, E. M. C. O. Teague, N. O. Palmer et al., "Paternal obesity initiates metabolic disturbances in two generations of mice with incomplete penetrance to the F2 generation and alters the transcriptional profile of testis and sperm microRNA content," The FASEB Journal, vol. 27, no. 10, pp. 4226-4243, 2013.

[150] A. B. Rodgers, C. P. Morgan, S. L. Bronson, S. Revello, and T. L. Bale, "Paternal stress exposure alters sperm MicroRNA content and reprograms offspring HPA stress axis regulation," The Journal of Neuroscience, vol. 33, no. 21, pp. 9003-9012, 2013.

[151] K. Gapp, A. Jawaid, P. Sarkies et al., "Implication of sperm RNAs in transgenerational inheritance of the effects of early trauma in mice," Nature Neuroscience, vol. 17, no. 5, pp. 667-669, 2014.

[152] E. J. Radford, M. Ito, H. Shi et al., "In utero undernourishment perturbs the adult sperm methylome and intergenerational metabolism," Science, vol. 345, no. 6198, Article ID 1255903, 2014.

[153] B. R. Carone, L. Fauquier, N. Habib et al., "Paternally induced transgenerational environmental reprogramming of metabolic gene expression in mammals," Cell, vol. 143, no. 7, pp. 1084-1096, 2010.

[154] R. Lambrot, C. Xu, S. Saint-Phar et al., "Low paternal dietary folate alters the mouse sperm epigenome and is associated with negative pregnancy outcomes," Nature Communications, vol. 4, article 2889, 2013.

[155] X. Tian and F. J. Diaz, "Acute dietary zinc deficiency before conception compromises oocyte epigenetic programming and disrupts embryonic development," Developmental Biology, vol. 376, no. 1, pp. 51-61, 2013.

[156] Y. Wei, C.-R. Yang, Y.-P. Wei et al., "Paternally induced transgenerational inheritance of susceptibility to diabetes in mammals," Proceedings of the National Academy of Sciences of the United States of America, vol. 111, no. 5, pp. 1873-1878, 2014. 
[157] Z.-J. Ge, X.-W. Liang, L. Guo et al., "Maternal diabetes causes alterations of DNA methylation statuses of some imprinted genes in murine oocytes," Biology of Reproduction, vol. 88, no. 5, article 117, 9 pages, 2013.

[158] Z. J. Ge, S. M. Luo, F. Lin et al., "DNA methylation in oocytes and liver of female mice and their offspring: Effects of high-fatdiet-induced obesity," Environmental Health Perspectives, vol. 122, no. 2, pp. 159-164, 2014.

[159] M. D. Anway, A. S. Cupp, N. Uzumcu, and M. K. Skinner, "Toxicology: epigenetic transgenerational actions of endocrine disruptors and male fertility," Science, vol. 308, no. 5727, pp. 1466-1469, 2005.

[160] K. Inawaka, M. Kawabe, S. Takahashi et al., "Maternal exposure to anti-androgenic compounds, vinclozolin, flutamide and procymidone, has no effects on spermatogenesis and DNA methylation in male rats of subsequent generations," Toxicology and Applied Pharmacology, vol. 237, no. 2, pp. 178-187, 2009.

[161] C. Stouder and A. Paoloni-Giacobino, "Transgenerational effects of the endocrine disruptor vinclozolin on the methylation pattern of imprinted genes in the mouse sperm," Reproduction, vol. 139, no. 2, pp. 373-379, 2010.

[162] C. Stouder and A. Paoloni-Giacobino, "Specific transgenerational imprinting effects of the endocrine disruptor methoxychlor on male gametes," Reproduction, vol. 141, no. 2, pp. 207216, 2011.

[163] E. Somm, C. Stouder, and A. Paoloni-Giacobino, "Effect of developmental dioxin exposure on methylation and expression of specific imprinted genes in mice," Reproductive Toxicology, vol. 35, no. 1, pp. 150-155, 2013.

[164] H.-H. Chao, X.-F. Zhang, B. Chen et al., "Bisphenol A exposure modifies methylation of imprinted genes in mouse oocytes via the estrogen receptor signaling pathway," Histochemistry and Cell Biology, vol. 137, no. 2, pp. 249-259, 2012.

[165] T. Trapphoff, M. Heiligentag, N. El Hajj, T. Haaf, and U. Eichenlaub-Ritter, "Chronic exposure to a low concentration of bisphenol A during follicle culture affects the epigenetic status of germinal vesicles and metaphase II oocytes," Fertility and Sterility, vol. 100, no. 6, pp. 1758.e1-1767.e1, 2013.

[166] T. Doshi, C. D’Souza, and G. Vanage, "Aberrant DNA methylation at Igf2-H19 imprinting control region in spermatozoa upon neonatal exposure to bisphenol $\mathrm{A}$ and its association with post implantation loss," Molecular Biology Reports, vol. 40, no. 8, pp. 4747-4757, 2013.

[167] C. Yauk, A. Polyzos, A. Rowan-Carroll et al., "Germ-line mutations, DNA damage, and global hypermethylation in mice exposed to particulate air pollution in an urban/industrial location," Proceedings of the National Academy of Sciences of the United States of America, vol. 105, no. 2, pp. 605-610, 2008.

[168] C. Stouder, E. Somm, and A. Paoloni-Giacobino, "Prenatal exposure to ethanol: a specific effect on the H19 gene in sperm," Reproductive Toxicology, vol. 31, no. 4, pp. 507-512, 2011.

[169] J. G. Knezovich and M. Ramsay, "The effect of preconception paternal alcohol exposure on epigenetic remodeling of the H19 and Rasgrf1 imprinting control regions in mouse offspring," Frontiers in Genetics, vol. 3, article 10, 2012.

[170] N. A. Kedia-Mokashi, L. Kadam, M. Ankolkar, K. Dumasia, and N. H. Balasinor, "Aberrant methylation of multiple imprinted genes in embryos of tamoxifen-treated male rats," Reproduction, vol. 146, no. 2, pp. 155-168, 2013.

[171] S. Pathak, N. Kedia-Mokashi, M. Saxena et al., "Effect of tamoxifen treatment on global and insulin-like growth factor
2-H19 locus-specific DNA methylation in rat spermatozoa and its association with embryo loss," Fertility and Sterility, vol. 91, no. 5, supplement, pp. 2253-2263, 2009.

[172] D. Xia, N. Parvizi, Y. Zhou et al., "Paternal fenvalerate exposure influences reproductive functions in the offspring," Reproductive Sciences, vol. 20, no. 11, pp. 1308-1315, 2013.

[173] J.-Q. Zhu, Y.-J. Si, L.-Y. Cheng et al., "Sodium fluoride disrupts DNA methylation of $\mathrm{H} 19$ and Peg3 imprinted genes during the early development of mouse embryo," Archives of Toxicology, vol. 88, no. 2, pp. 241-248, 2014.

[174] S. Pathak, M. Saxena, R. D'Souza, and N. H. Balasinor, "Disrupted imprinting status at the $\mathrm{H} 19$ differentially methylated region is associated with the resorbed embryo phenotype in rats," Reproduction, Fertility and Development, vol. 22, no. 6, pp. 939-948, 2010.

[175] B. G. Dias and K. J. Ressler, "Parental olfactory experience influences behavior and neural structure in subsequent generations," Nature Neuroscience, vol. 17, no. 1, pp. 89-96, 2014.

[176] C. P. Wild, "Environmental exposure measurement in cancer epidemiology," Mutagenesis, vol. 24, no. 2, pp. 117-125, 2009.

[177] F. Ricceri, M. Trevisan, V. Fiano et al., "Seasonality modifies methylation profiles in healthy people," PLoS ONE, vol. 9, no. 9, Article ID e106846, 2014.

[178] M.-A. Bind, A. Zanobetti, A. Gasparrini et al., "Effects of temperature and relative humidity on DNA methylation," Epidemiology, vol. 25, no. 4, pp. 561-569, 2014.

[179] V. Bollati, A. Baccarelli, S. Sartori et al., "Epigenetic effects of shiftwork on blood DNA methylation," Chronobiology International, vol. 27, no. 5, pp. 1093-1104, 2010.

[180] Y. Zhu, R. G. Stevens, A. E. Hoffman et al., "Epigenetic impact of long-term shiftwork: pilot evidence from circadian genes and whole-genome methylation analysis," Chronobiology International, vol. 28, no. 10, pp. 852-861, 2011.

[181] F. Shi, X. Chen, A. Fu et al., "Aberrant DNA methylation of miR219 promoter in long-term night shiftworkers," Environmental and Molecular Mutagenesis, vol. 54, no. 6, pp. 406-413, 2013.

[182] D. I. Jacobs, J. Hansen, A. Fu et al., "Methylation alterations at imprinted genes detected among long-term shiftworkers," Environmental and Molecular Mutagenesis, vol. 54, no. 2, pp. 141-146, 2013.

[183] A. L. Teh, H. Pan, L. Chen et al., "The effect of genotype and in utero environment on interindividual variation in neonate DNA methylomes," Genome Research, vol. 24, no. 7, pp. 10641074, 2014.

[184] S. Shah, A. F. McRae, R. E. Marioni et al., "Genetic and environmental exposures constrain epigenetic drift over the human life course," Genome Research, vol. 24, no. 11, pp. 17251733, 2014.

[185] J. Kim, K. Kim, H. Kim, G. Yoon, and K. Lee, "Characterization of age signatures of DNA methylation in normal and cancer tissues from multiple studies," BMC Genomics, vol. 15, no. 1, p. 997, 2014.

[186] L. M. Reynolds, J. R. Taylor, J. Ding et al., "Age-related variations in the methylome associated with gene expression in human monocytes and T cells," Nature Communications, vol. 5, p. 5366, 2014.

[187] J. L. Mcclay, K. A. Aberg, S. L. Clark et al., "A methylomewide study of aging using massively parallel sequencing of the methyl-CpG-enriched genomic fraction from blood in over 700 subjects," Human Molecular Genetics, vol. 23, no. 5, pp. 11751185, 2014. 
[188] S. D. Fouse, R. P. Nagarajan, and J. F. Costello, "Genome-scale DNA methylation analysis," Epigenomics, vol. 2, no. 1, pp. 105117, 2010.

[189] P. W. Laird, "Principles and challenges of genome-wide DNA methylation analysis," Nature Reviews Genetics, vol. 11, no. 3, pp. 191-203, 2010.

[190] E. Meaburn and R. Schulz, "Next generation sequencing in epigenetics: insights and challenges," Seminars in Cell and Developmental Biology, vol. 23, no. 2, pp. 192-199, 2012.

[191] K. Mensaert, S. Denil, G. Trooskens, W. van Criekinge, O. Thas, and T. de Meyer, "Next-generation technologies and data analytical approaches for epigenomics," Environmental and Molecular Mutagenesis, vol. 55, no. 3, pp. 155-170, 2014.

[192] A. S. Yang, M. R. H. Estécio, K. Doshi, Y. Kondo, E. H. Tajara, and J.-P. J. Issa, "A simple method for estimating global DNA methylation using bisulfite PCR of repetitive DNA elements," Nucleic Acids Research, vol. 32, no. 3, article e38, 2004.

[193] J. Tost and I. G. Gut, "DNA methylation analysis by pyrosequencing," Nature Protocols, vol. 2, no. 9, pp. 2265-2275, 2007.

[194] M. Bibikova, B. Barnes, C. Tsan et al., "High density DNA methylation array with single CpG site resolution," Genomics, vol. 98, no. 4, pp. 288-295, 2011.

[195] E. M. Price, A. M. Cotton, M. S. Peñaherrera, D. E. McFadden, M. S. Kobor, and W. P. Robinson, "Different measures of 'genome-wide' DNA methylation exhibit unique properties in placental and somatic tissues," Epigenetics, vol. 7, no. 6, pp. 652663, 2012.

[196] T. Mikeska and J. M. Craig, "DNA methylation biomarkers: cancer and beyond," Genes, vol. 5, no. 3, pp. 821-864, 2014.

[197] A. Molaro, E. Hodges, F. Fang et al., "Sperm methylation profiles reveal features of epigenetic inheritance and evolution in primates," Cell, vol. 146, no. 6, pp. 1029-1041, 2011.

[198] C. Krausz, J. Sandoval, S. Sayols et al., "Novel insights into DNA methylation features in spermatozoa: stability and peculiarities," PLoS ONE, vol. 7, no. 10, Article ID e44479, 2012. 

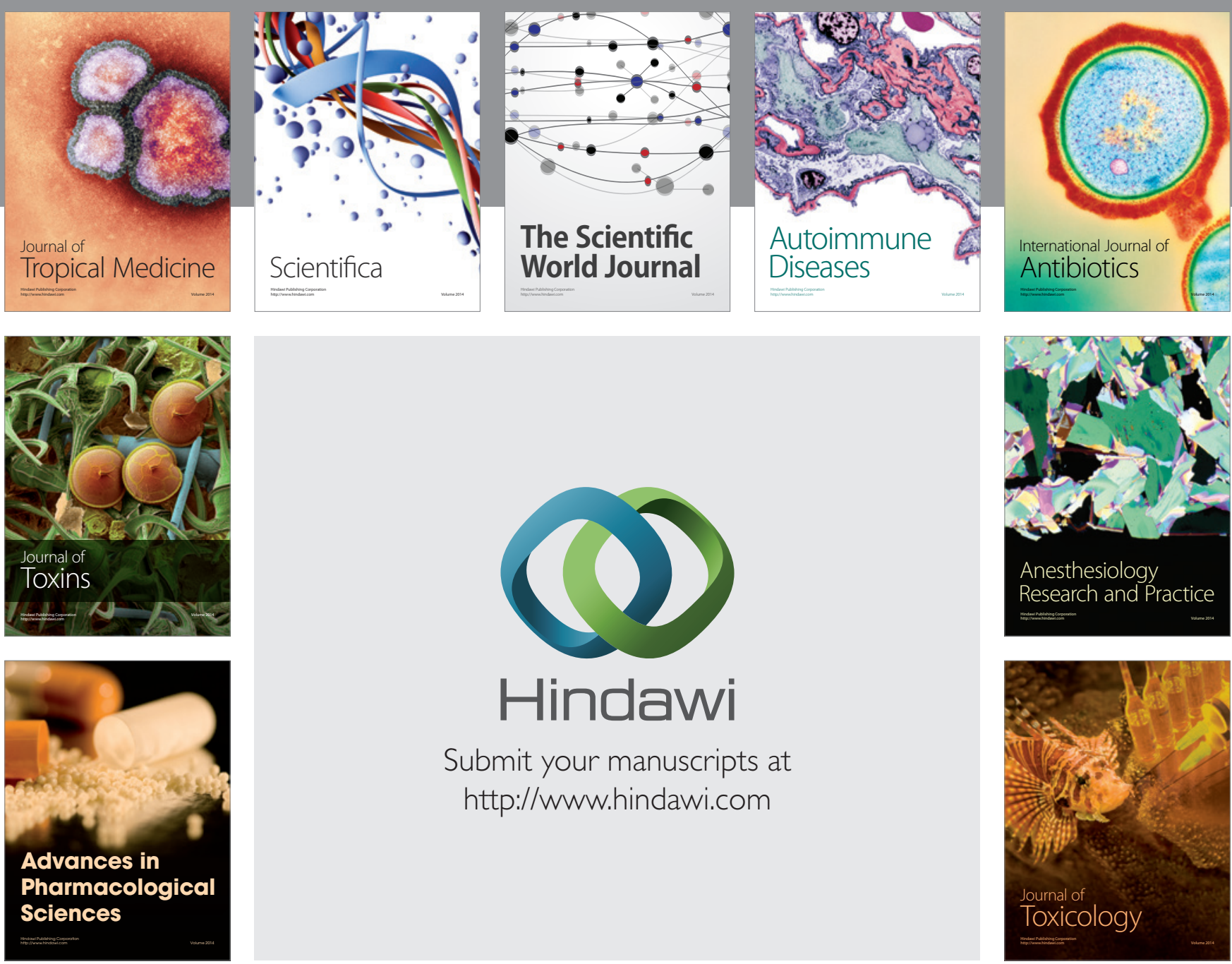

\section{Hindawi}

Submit your manuscripts at

http://www.hindawi.com
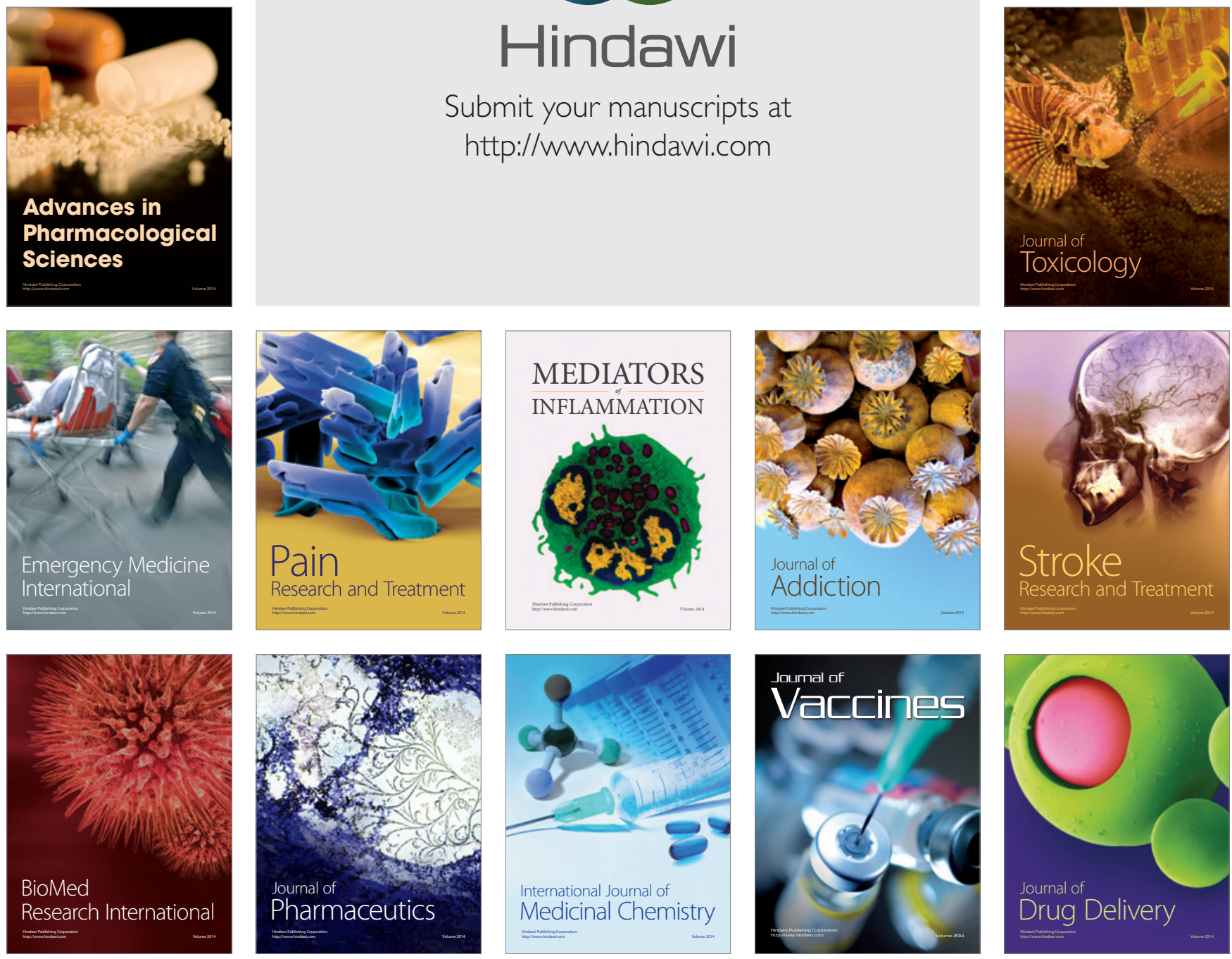